\title{
Management of Pulmonary Arterial Hypertension
}

\author{
Jennalyn D. Mayeux ${ }^{1}$ • Irene Z. Pan ${ }^{2}$ • John Dechand ${ }^{2} \cdot$ Joshua A. Jacobs $^{2} \cdot$ Tara L. Jones $^{3} \cdot$ Stephen H. McKellar ${ }^{4}$. \\ Emily Beck ${ }^{1} \cdot$ Nathan D. Hatton ${ }^{1} \cdot$ John J. Ryan ${ }^{3}$
}

Accepted: 12 August 2020 / Published online: 27 November 2020

(C) Springer Science+Business Media, LLC, part of Springer Nature 2020, corrected publication 2020

\begin{abstract}
Purpose of Review This review focuses on the therapeutic management and individualized approach to Group 1 pulmonary arterial hypertension (PAH), utilizing Food and Drug Administration-approved PAH-specific therapies and various interventional and surgical options for PAH.

Recent Findings The paradigm for the optimal management of PAH has shifted in recent years. Upfront combination therapy with an endothelin receptor antagonist and a phosphodiesterase 5 inhibitor is now widely accepted as standard of care. In addition, there is increasing emphasis on starting prostanoids early in order to delay time to clinical worsening. However, less is known regarding which prostanoid agent to initiate and the optimum time to do so. In order to facilitate shared decisionmaking, there is an increasing need for decision tools based on guidelines and collective clinical experiences to navigate between pharmacologic and interventional treatments, as well as explore innovative, therapeutic pathways for PAH.

Summary The management of PAH has become increasingly complex. With a growing number of PAH-specific therapies, intimate knowledge of the therapeutics and the potential barriers to adherence are integral to providing optimal care for this highrisk patient population. While current PAH-specific therapies largely mediate their effects through pulmonary vasodilation, ongoing research efforts are focused on ways to disrupt the mechanisms leading to pulmonary vascular remodeling. By targeting aberrations identified in the metabolism and proliferative state of pulmonary vascular cells, novel PAH treatment pathways may be just on the horizon.
\end{abstract}

Keywords Pulmonary hypertension $\cdot$ Therapeutics $\cdot$ Right heart failure $\cdot$ Pharmacology $\cdot$ Prostaglandin $\cdot$ Prostacyclin

\section{Introduction}

Pulmonary hypertension (PH) describes an abnormal elevation in pulmonary arterial blood pressure [1]. The World

Jennalyn D. Mayeux and Irene Z. Pan contributed equally to this work.

This article is part of the Topical Collection on Secondary Prevention and Intervention

John J. Ryan

john.ryan@hsc.utah.edu

1 Division of Pulmonary and Critical Care Medicine, Department of Medicine, University of Utah, Salt Lake City, UT 84132, USA

2 Department of Pharmacy, University of Utah Health, Salt Lake City, UT 84132, USA

3 Division of Cardiovascular Medicine, Department of Medicine, University of Utah, 30 North 1900 East, Room 4A100, Salt Lake City, UT 84132, USA

4 Division of Cardiothoracic Surgery, Department of Surgery, University of Utah, Salt Lake City, UT 84132, USA
Health Organization (WHO) classifies $\mathrm{PH}$ into five groups based on shared histology and pathophysiology. Group 1 pulmonary arterial hypertension $(\mathrm{PAH})$ is a rare form of $\mathrm{PH}$ characterized by plexogenic vascular remodeling. Causes for Group 1 PAH include idiopathic and familial PH, as well as $\mathrm{PH}$ associated with conditions such as collagen vascular disease, congenital shunts, cirrhosis and portal hypertension, human immunodeficiency virus (HIV), hemoglobinopathies, and schistosomiasis. Group $1 \mathrm{PAH}$ also includes $\mathrm{PH}$ associated with drugs, such as anorexigens or amphetamines. Group 2 $\mathrm{PH}$ is the collection of $\mathrm{PH}$ syndromes resulting from left ventricular (LV) or left-sided valvular disease, such as heart failure with reduced ejection fraction (HFrEF), heart failure with preserved ejection fraction (HFpEF), or valvular heart disease. Group $3 \mathrm{PH}$ is PH secondary to chronic lung diseases, hypoxia, or both. This group of $\mathrm{PH}$ is typically characterized by mild elevations in pulmonary artery pressure (PAP), relative to patients with other types of PH. Group $4 \mathrm{PH}$ is due to pulmonary arterial obstruction and commonly known as chronic thromboembolic pulmonary hypertension (CTEPH). 
This category of $\mathrm{PH}$ is particularly unique as it represents a curable form of $\mathrm{PH}$ that does not require lung transplantation. Group 5 PH represents a heterogeneous collection of PH syndromes secondary to systemic diseases (e.g., sarcoidosis, histiocytosis X), hematological disorders (e.g., polycythemia vera, chronic myeloid leukemia), and extrinsic compression of the pulmonary artery. This classification system has practical significance as contemporary PAH treatments have increasingly demonstrated inconsistent benefit and even potential signals of harm across other types of $\mathrm{PH}$ [2].

The focus of this review is the therapeutic management of Group 1 PAH. The review will discuss approved and emerging treatment pathways, Food and Drug Administration (FDA)-approved $\mathrm{PAH}$-specific therapies, and personalization of $\mathrm{PAH}$ care, in addition to interventional and surgical options for $\mathrm{PAH}$.

\section{Currently Approved Treatment Pathways}

The pathogenesis of PAH is diverse and very complex. As more clinical trial and registry data becomes available, our understanding of the development and progression of this rare disease continues to evolve. Multiple mechanisms occur at the cellular and tissue level that potentiate smooth muscle cell proliferation, endothelial cell dysfunction, inflammation, and remodeling of the pulmonary vasculature. Together, these physiological alterations result in pathologic transformations leading to excessive vasoconstriction, medial hypertrophy, intimal fibrosis, and formation of plexiform lesions [3, 4]. Contemporary PAH therapies target one of three major pathways implicated in disease progression: nitric oxide (NO), endothelin-1 (ET-1), and prostacyclin $\left(\mathrm{PGI}_{2}\right)$ pathways. In a small minority of patients with $\mathrm{PAH}$, excessive vasoconstriction plays a predominant role in increasing pulmonary vascular resistance (PVR) - mediated in large part by an influx of calcium via long-lasting calcium channels in vascular smooth muscle cells [5]. Targeting one or more of these pathways has become the current standard of practice for the medical management of PAH [6]. Therapies are available orally (Table 1) and in parenteral and inhaled forms (Table 2). Clinical trials have shown that these therapies play an important role in improving quality of life, and some have even shown a reduction in mortality rates in $\mathrm{PAH}$ (Table 3 ). However, $\mathrm{PAH}$ remains a high mortality disease with no cure.

\section{Nitric Oxide Pathway}

In $\mathrm{PAH}, \mathrm{NO}$ production is chronically impaired. $\mathrm{NO}$ is an endothelium-derived vasoactive mediator that increases the production of cyclic guanosine monophosphate (cGMP) through the activation of soluble guanylate cyclase (sGC). In doing so, $\mathrm{NO}$ acts to stimulate vasodilation and inhibit proliferation within vascular smooth muscle cells $[3,4]$. Currently, there are two drug classes targeting this pathway, phosphodiesterase type-5 inhibitors (PDE5i) and sGC stimulators. Phosphodiesterase type-5 (PDE5) is an enzyme found in high concentrations within the pulmonary vasculature that works to catalyze the conversion of cGMP to guanosine monophosphate (GMP). Inhibitors of the PDE-5 enzyme, such as sildenafil and tadalafil, enhance the NO-dependent, cGMPmediated pathway by preventing the breakdown of cGMP, while riociguat, an $\mathrm{SGC}$ stimulator, works directly to increase the production of cGMP, resulting in vasodilation and antiproliferative effects [57].

\section{Endothelin Pathway}

Endothelin-1 is a potent vasoconstrictor and key driver of pulmonary vascular remodeling through its actions on endothelin receptor $\mathrm{A}\left(\mathrm{ET}_{\mathrm{A}}\right)$ and endothelin receptor $\mathrm{B}$ $\left(\mathrm{ET}_{\mathrm{B}}\right)$ [3]. Endothelin-1 is upregulated in the vascular endothelial cells of patients with pulmonary hypertension. By binding to $\mathrm{ET}_{\mathrm{A}}$ and $\mathrm{ET}_{\mathrm{B}}$ receptors located in smooth muscle cells, ET-1 stimulates cellular proliferation, fibrosis, inflammation, and vasoconstriction [4, 58]. The effects of ET-1 via $\mathrm{ET}_{\mathrm{B}}$ on endothelial cells result in increased production of prostacyclin and NO and subsequent vasodilation $[3,59]$. Both $\mathrm{ET}_{\mathrm{A}}$ and $\mathrm{ET}_{\mathrm{B}}$ receptors are found in high concentrations within the pulmonary vasculature, and as such, serve as an important focus for targeted drug therapy [59]. There are currently three FDAapproved endothelin-receptor antagonists (ERA) with varying degrees of affinity for $\mathrm{ET}_{\mathrm{A}}$ and $\mathrm{ET}_{\mathrm{B}}$ receptors: ambrisentan, bosentan, and macitentan.

\section{Prostacyclin Pathway}

The final pathway involves prostacyclin, a potent vasodilator produced predominantly in the vascular endothelium. The vasodilatory effects of prostacyclin, also referred to as $\mathrm{PGI}_{2}$, result from $\mathrm{PGI}_{2}$ stimulation of the prostaglandin 2 (IP) receptor, leading to increased generation of cyclic adenosine monophosphate (cAMP). Additionally, $\mathrm{PGI}_{2}$ inhibits platelet aggregation and possesses antiproliferative properties [3, 60]. However, in $\mathrm{PAH}, \mathrm{PGI}_{2}$ synthesis is suppressed, whereas levels of thromboxane $\mathrm{A}_{2}$, an endogenous vasoconstrictor and platelet agonist, are increased [61]. Drug therapies targeting this imbalance within the pulmonary arteries include $\mathrm{PGI}_{2}$ analogs, such as epoprostenol, treprostinil, and iloprost, and $\mathrm{PGI}_{2}$ receptor agonists, such as selexipag [62].

\section{Calcium Channel Blockers}

Calcium channel blockers (CCB) are indicated in patients with a positive acute vasoreactivity test. Common CCBs used for 


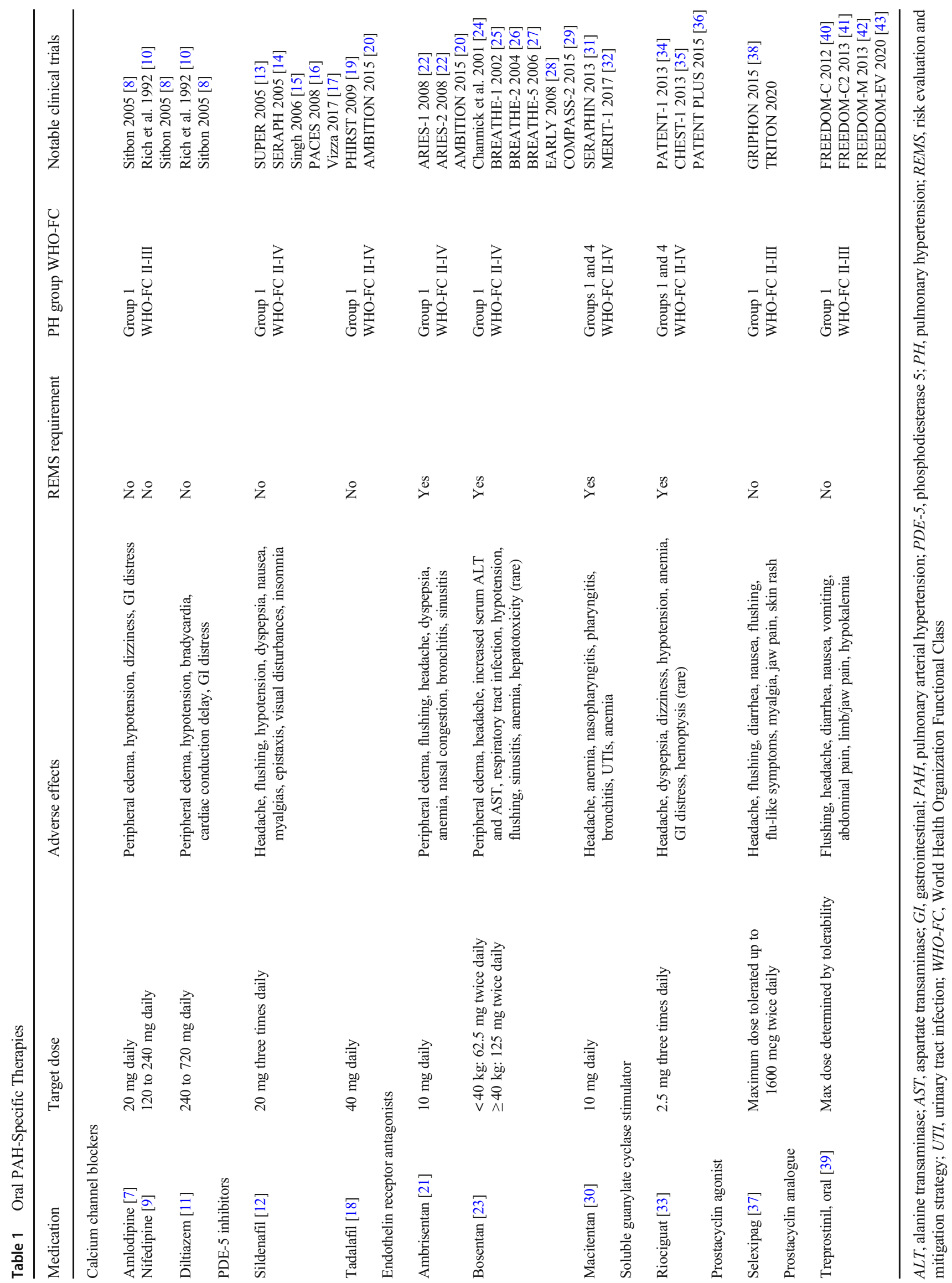


PAH include nifedipine, amlodipine, and diltiazem. Diltiazem is typically reserved for patients with tachycardia or other comorbidities requiring rate control and avoided in patients with worsening right ventricular failure or bradycardia. Effective doses are higher than what is typically seen for other indications (Table 1). Patients should be started on a low dose and gradually titrated up as tolerated [57]. Common adverse drug reactions include peripheral edema, systemic hypotension, nausea, gastrointestinal distress, and bradycardia, in the setting of diltiazem [7, 9, 11]. Monotherapy with a CCB is indicated only in patients who achieve the desired dose, establish improved hemodynamics after 3-4 months of therapy, and maintain WHO Functional Class (FC) I-II status. In patients who cannot tolerate therapy or experience worsening hemodynamics or functionality, alternative $\mathrm{PAH}$-specific therapy is recommended [57].

Calcium channel blockers were initially studied in the acute setting in patients who were given nifedipine $20 \mathrm{mg}$ or diltiazem $60 \mathrm{mg}$ hourly. Of the patients who responded to CCB therapy, the mean reduction in PVR and PAP were $60 \%$ and $48 \%$, respectively [63]. A subsequent study demonstrated improved 5-year survival in patients who responded to CCBs compared to those who did not (94\% vs. $55 \% ; p=0.003$ ) [10]. However, less than $10 \%$ of PAH patients were found to be long-term responders to CCB therapy $[8,10,64]$.

\section{Phosphodiesterase Type-5 Inhibitors}

For over a decade, PDE5is have remained the most widely prescribed class of PAH-specific therapies. These agents are arguably the easiest to initiate due to relative ease of procurement and generic availability. As such, these agents are typically the initial therapy prescribed for patients diagnosed with PAH.

Although initially approved in 1998 for use in erectile dysfunction [65], the role of sildenafil soon expanded due to its actions on PDE5 receptors within the pulmonary vasculature, and sildenafil was approved by the FDA for the treatment of PAH in 2005 [12]. Early sildenafil trials, the vast majority of which included $\leq 30$ patients, tested doses up to $100 \mathrm{mg}$ three times daily [66]. In these studies, sildenafil demonstrated efficacy in a number of clinical outcomes with incremental benefit at higher sildenafil doses. The 2005 SUPER trial, a randomized, placebo-controlled trial, demonstrated improvements in WHO-FC, reduction in mean PAP, and reduction in PVR that incrementally improved with higher doses [13]. No significant difference was found between sildenafil $20 \mathrm{mg}$, $40 \mathrm{mg}$, and $80 \mathrm{mg}$ three times daily in WHO-FC II-III, treatment-naïve patients with respect to the primary outcome of 6min walk distance (6MWD) [13]. Moreover, sildenafil has also been shown to improve outcomes even when added to advanced therapies such as intravenous (IV) epoprostenol. 


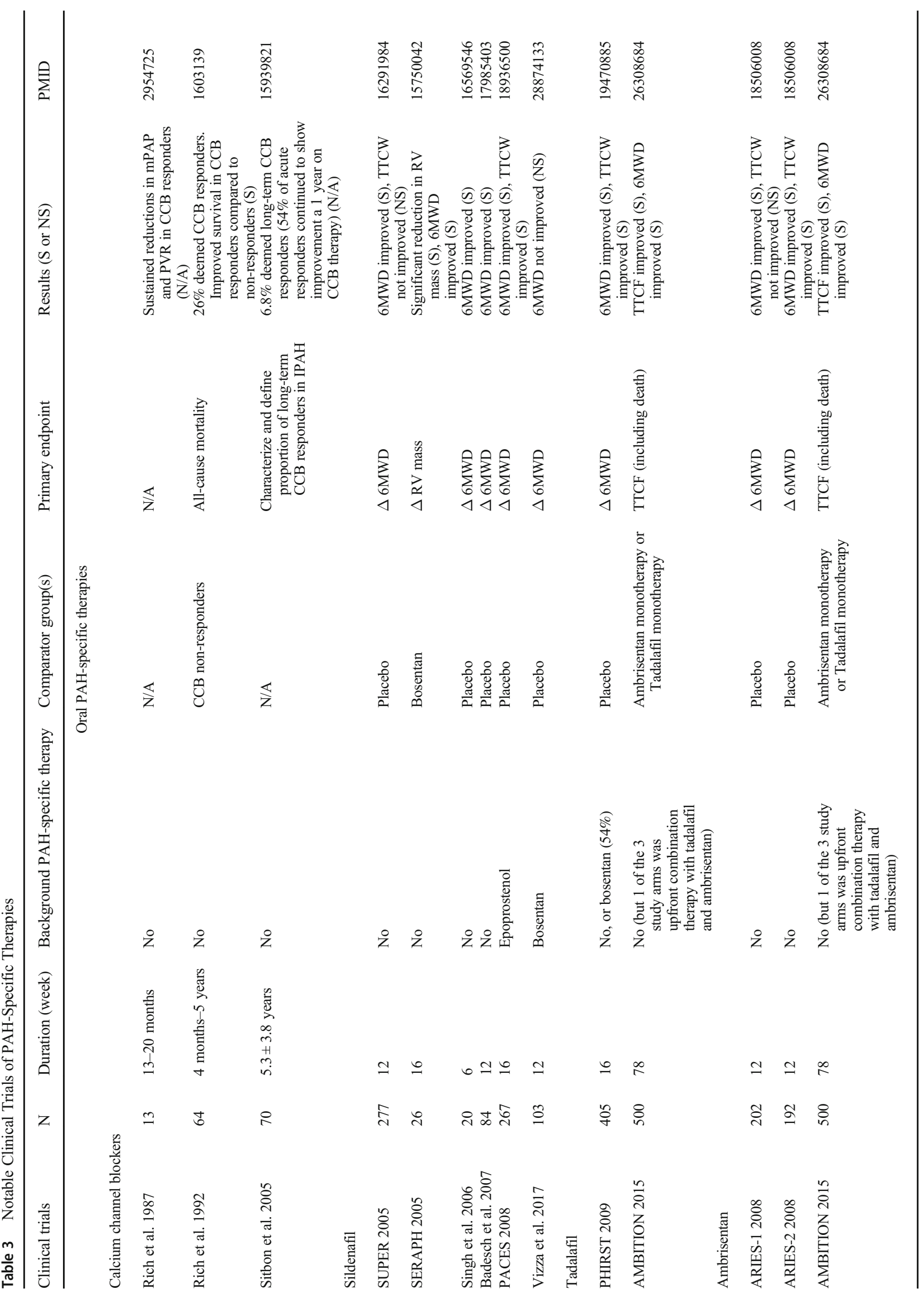




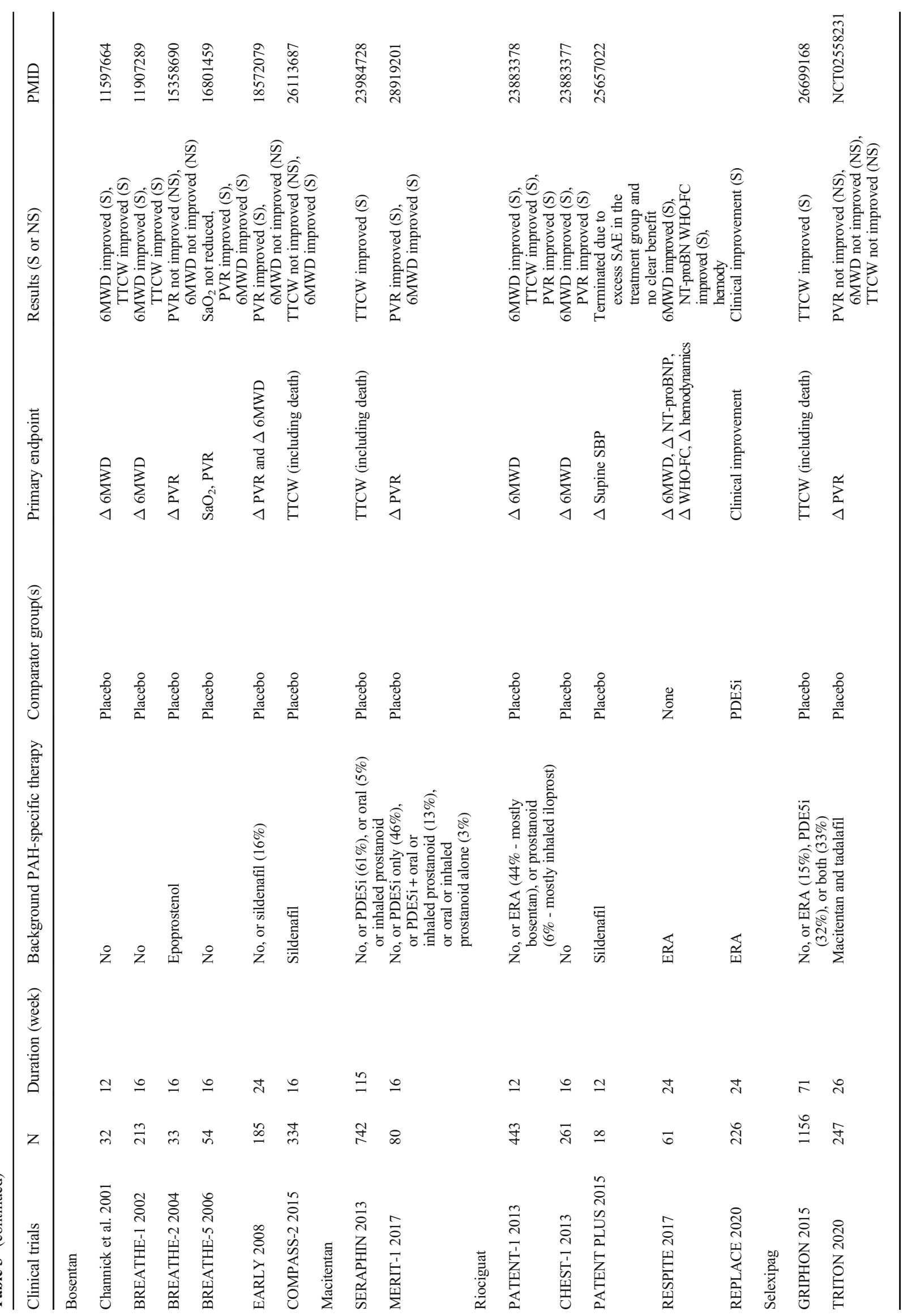




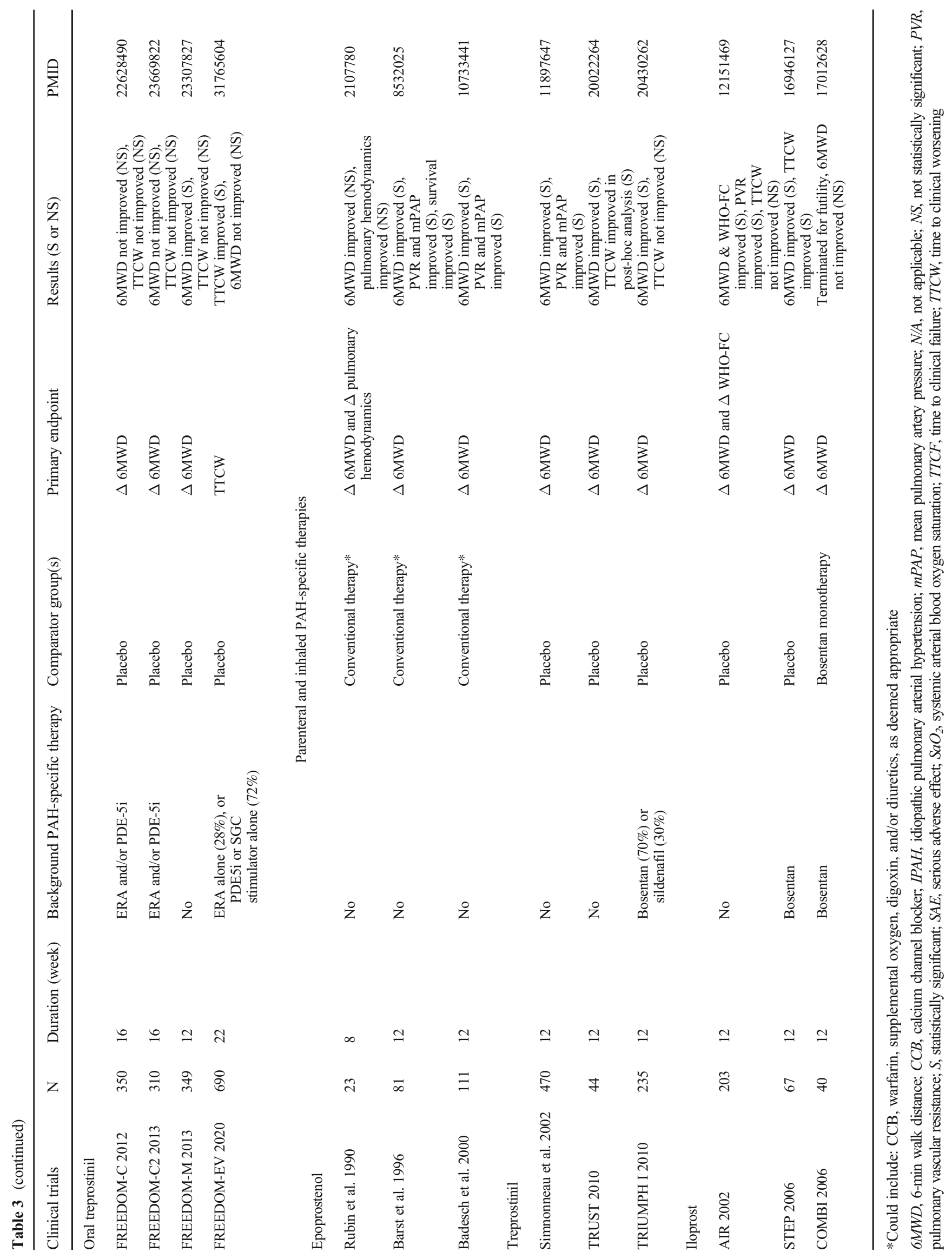


The 2008 PACES trial randomized patients on IV epoprostenol to sildenafil $80 \mathrm{mg}$ three times daily or placebo [16]. The addition of sildenafil at $80 \mathrm{mg}$ three times daily to an IV prostanoid improved 6MWD in comparison to the placebo arm. This further solidified its place in therapy and added to the data supporting combination therapy. Although there has been some interest over the years regarding use of higher sildenafil doses such as $40 \mathrm{mg}$ or even $80 \mathrm{mg}$ three times daily, the large sample size data available do not support this strategy. Based on data from the SUPER trial, it has been hypothesized that adequate inhibition of PDE5 is achieved with $20 \mathrm{mg}$ dosed three times daily [13]. Thus, $20 \mathrm{mg}$ three times daily became the FDA-approved dose for PAH [12]. Notwithstanding the evidence for higher doses, obtaining insurance approval for doses higher than the FDA-approved dose of $20 \mathrm{mg}$ three times daily is very difficult.

The other widely available agent in this class, tadalafil, received FDA-approval in 2009. Tadalafil is more convenient than its predecessor given its longer half-life and once daily dosing [18]. Unlike the mixed data with sildenafil dosing, the PHIRST trial demonstrated tadalafil $40 \mathrm{mg}$ once daily was indisputably the target dose [19]. Tadalafil $40 \mathrm{mg}$ daily demonstrated improvements in 6MWD and time to clinical worsening (TTCW) in a mixture of treatment-naïve patients and patients on background therapy with bosentan. Both PDE5is carry similar adverse effect profiles, the most common being headache, flushing, myalgia, and dyspepsia. These adverse effects rarely result in the need for discontinuation and typically resolve over time.

\section{Soluble Guanylate Cyclase Stimulators}

As a member of the newest class of PAH-specific therapies, riociguat, a sGC stimulator, has established its role among the armamentarium of agents that target the NO pathway. In addition to its role in Group $1 \mathrm{PAH}$, riociguat is currently the only PAH-specific therapy that also carries FDA approval for Group 4 PH, or inoperable or persistent CTEPH [6, 57]. In the PATENT-1 and CHEST-1 trials, riociguat $2.5 \mathrm{mg}$ three times daily significantly improved the primary outcome of 6MWD by $30 \mathrm{~m}$ and $39 \mathrm{~m}$, in PAH and CTEPH, respectively [34, 35]. In PATENT-1, this effect was seen in both treatment-naïve patients, as well as patients on background therapy with an ERA. The secondary endpoints of reduction in PVR and Nterminal probrain natriuretic peptide (NT-proBNP) and improvement in WHO-FC were consistent between both trials. Though only PATENT-1 showed an improvement in TTCW, this endpoint should be interpreted with caution due to the small overall number of events (8 vs. 3) [6]. In addition, the RESPITE trial demonstrated a potential benefit in transitioning from PDE5i therapy to riociguat in WHO-FC III PAH patients on background ERA therapy [67]. The subsequent REPLACE trial showed benefit with switching stable intermediate risk patients from PDE5i therapy to riociguat (https://pharmaceuticalbusiness-review.com/news/ bayer-adempas-phase-4-trial/).

Adverse effects were consistent between both trials, most commonly being headache, dyspepsia, dizziness, and hypotension. The latter is an adverse effect that is particularly unique to riociguat as compared to other oral therapies for $\mathrm{PAH}$. The average mean arterial pressure reduction in both trials was $9 \mathrm{mmHg}$. Thus, riociguat requires slow uptitration to the target dose of $2.5 \mathrm{mg}$ three times daily. It is typically started at $1 \mathrm{mg}$ three times daily and increased by $0.5 \mathrm{mg}$ three times daily at 2 week intervals if systolic blood pressure remains > $95 \mathrm{mmHg}$. Of note, PDE5is and sGC stimulators should not be used in combination due to the duplication of the NO pathway and pronounced hypotension as evidenced in the PATENT PLUS trial [36]. Riociguat requires females to enroll in the Risk Evaluation and Mitigation Strategy (REMS) program due to the teratogenicity of the drug.

\section{Endothelin Receptor Antagonists}

Three ERAs are currently FDA-approved for the treatment of PAH. All three agents are teratogenic and require both prescribers and female patients to be enrolled in the REMS program. The REMS require females of reproductive potential to establish a negative pregnancy test prior to therapy initiation, monthly during therapy, and 1 month following therapy discontinuation. Additionally, bosentan carries an additional REMS program requirement of monthly liver function tests to monitor for hepatotoxicity. Bosentan is the only FDAapproved ERA for the pediatric population and is typically avoided in adults due to hepatotoxic risk. Other common adverse drug reactions for ERAs include edema, headaches, flulike symptoms, nasal congestion, anemia, and urinary tract infection, in the setting of macitentan [21, 23, 30]. Doses for the following agents are as follows: bosentan $62.5-125 \mathrm{mg}$ twice daily, ambrisentan 5-10 mg daily, and macitentan $10 \mathrm{mg}$ daily. Doses for bosentan and ambrisentan are usually started low and titrated up as tolerated. Endothelin receptor antagonists are recommended in WHO-FC II-III patients [57].

Bosentan has been studied in a wide variety of trials and has been shown to improve cardiac index, PVR, patientreported dyspnea, 6MWD, and TTCW [14, 24, 25, 27-29]. In the 24-week Study 351 trial, 32 patients with idiopathic or hereditary PAH or PAH associated with scleroderma were randomized to bosentan or placebo. All patients were WHOFC III and were not on any PAH-specific medications at baseline. Patients on bosentan had a 70-m improvement in 6MWD from baseline as compared to a worsening of $6 \mathrm{~m}$ in the placebo group [24]. Bosentan continued to demonstrate improvements in WHO-FC III patients in the SERAPH, BREATHE-1, 
and BREATHE-5 trials $[14,25,27]$ and also showed benefit in WHO-FC II patients in the EARLY trial [28]. The COMPASS2 trial established additional benefits in patients already on stable doses of sildenafil [29]. Within the ARIES1 and ARIES-2 trials, ambrisentan demonstrated improvements in 6MWD, TTCW, and WHO-FC at 12 weeks and at 48 weeks [22]. Macitentan showed favorable outcomes in TTCW, 6MWD, WHO-FC, and PAH-related death and hospitalization in WHO-FC II-III PAH patients, the majority of which were on concomitant PDE5i in the SERAPHIN trial [31]. In the 2017 MERIT-1 trial, macitentan was also found to reduce PVR and improve cardiac index and 6MWD in WHO-FC II-III CTEPH patients [32].

\section{Parenteral and Inhaled Prostanoids}

As the first class of PAH-specific therapies to become available, the prostanoid class came as a breakthrough therapy for this disease. All treatments prior to the FDA approval of epoprostenol were considered adjunctive or supportive therapies [57]. The prostanoid class is indisputably the most diverse class with agents available via oral, inhalation, IV, and subcutaneous (SQ) routes of administration (Fig. 1). The three parenteral and inhaled prostanoids are epoprostenol, treprostinil, and iloprost.

Parenteral prostanoids (i.e., epoprostenol, treprostinil) have maintained their role as the only class with a class I recommendation for WHO-FC IV patients [57]. Epoprostenol, the sole synthetic prostacyclin, is also the only PAH-specific therapy to have shown improved survival in a randomized, controlled trial [46]. The primary outcome of this 12-week trial, 6MWD, was improved by $31 \mathrm{~m}$ compared to placebo. Similarly, the stable prostacyclin analogue, treprostinil, showed 16-m 6MWD improvement as compared to placebo in its respective randomized, controlled trial [50]. Though this improvement in 6MWD may not seem impressive as an overall value when compared to what was shown with PDE5is or ERAs, two key factors must be taken into consideration. First, $>90 \%$ of patients were WHO-FC III or IV at baseline between both trials, representing a population with much more advanced disease. Second, the mean dose achieved at 12 weeks was 9.2 and $9.3 \mathrm{ng} / \mathrm{kg} / \mathrm{min}[46,50]$. In our experience, consistent with most practices internationally, maintenance doses of continuous infusion prostanoids are typically targeted to achieve doses of $40 \mathrm{ng} / \mathrm{kg} / \mathrm{min}$, or higher, as tolerated. Therefore, as serum concentrations are linearly increased at doses up to $125 \mathrm{ng} / \mathrm{kg} / \mathrm{min}$ [48], coupled with further improvement as shown by Simmoneau and colleagues in patients in the highest quartile of treprostinil doses (i.e., > $13.8 \mathrm{ng}$ per kilogram per minute), larger increases in exercise capacity are anticipated at higher doses than mean doses achieved in the trials [50]. Epoprostenol and treprostinil are typically started at $1-2 \mathrm{ng} / \mathrm{kg} / \mathrm{min}$ and titrated upward at $1-2 \mathrm{ng} / \mathrm{kg} / \mathrm{min}$ every $12-24 \mathrm{~h}$, as tolerated. The most common and dose-limiting adverse effects of parenteral prostanoids during dose titration are headache, flushing, nausea, vomiting, jaw pain, diarrhea, abdominal pain, leg pain, arthralgias, myalgias, and hypotension. These occur during drug initiation and dose increases and typically resolve over time. Additionally, patients on SC treprostinil experience dose-limiting cutaneous site reactions due to a histamine-mediated response. This also resolves within 5-7 days maintained at a stable dose.

Given the need for continuous infusion of epoprostenol and parenteral treprostinil, the complexity of use of these agents cannot be overstated. First, all patients on chronic IV therapy require placement of an indwelling central venous catheter. Thus, patients must practice adequate line care hygiene to prevent the development of bloodstream infections [48]. Next, with a half-life of 3-5 $\min [44,48]$, epoprostenol requires fairly capable and health-literate patients to be able to adequately manage a continuous infusion pump. The possibility of interruption in therapy and subsequent rebound $\mathrm{PH}$ resulting in death makes epoprostenol a very high-risk therapy [44]. Treprostinil, with a much longer half-life of approximately $4 \mathrm{~h}$ [48], allows more time for patients to reestablish access, making therapy interruption less of a concern and affords the ability to use continuous SC infusion. For patients on continuous SC treprostinil, maintenance of a viable infusion site requires considerable lifestyle modifications as they must continually keep the site dry and intact to maintain site longevity.

The recent introduction of an implantable infusion pump for treprostinil has garnered clinician and patient interest given fewer maintenance requirements by the patient and the ability to shower and swim without concern for getting the pump or the infusion site wet. Long-term studies of the use of the implantable pump have described cases of pump failure and pump pocket infections [68].

Inhaled therapies offer an alternative route for WHOFC III-IV patients requiring a prostanoid. Iloprost, a prostacyclin analogue, and inhaled treprostinil, were both shown to improve 6MWD at 12 weeks [52, 54]. Though they obviate the need for central venous access and administration via a continuous infusion, both therapies are limited by frequency of dosing. Iloprost, dosed at 2.5-5 mcg six to nine times daily, requires around-the-clock administration at the target dose [53]. Though it requires less frequent administration, inhaled treprostinil still requires four administrations per day with a goal dose of 9 inhalations $(54 \mathrm{mcg}$ ) four times daily [49]. Furthermore, the nebulization device required for inhalation of both agents is bulky and must be carried by the patient during any excursions outside of the home if $>2 \mathrm{~h}$ for iloprost or $>4 \mathrm{~h}$ for treprostinil. The dose-limiting side effects of inhaled therapies are similar to parenteral with the addition of cough and throat irritation shortly after drug administration [49, 53]. 


\section{Oral / Inhaled Prostanoids}

Typically indicated in WHO-FC II-III; consider in WHO-FC IV patients deemed poor IV/SQ candidates

Specialty pharmacy nursing available at initiation of therapy and at prescriber specified intervals

\section{IV / SQ Prostanoids}

Treatment of choice in WHO-FC IV \& typically started inpatient Specialty pharmacy nursing support limited to pump management

Must have available support person and accommodating social environment

Potential risk with abrupt discontinuation

\begin{tabular}{|c|c|c|}
\hline & \multicolumn{2}{|c|}{ Oral Prostanoids } \\
\hline & Selexipag & Treprostinil \\
\hline 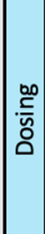 & $\begin{array}{l}\text { Starting dose: } \\
200 \text { mcg BID } \\
\text { Titrate by } 200 \\
\text { mcg weekly up } \\
\text { to } 1600 \text { mcg BID }\end{array}$ & $\begin{array}{l}\text { Starting dose: } \\
0.125 \text { mcg TID } \\
\text { Titrate by } 0.125 \\
\text { mg no more } \\
\text { frequently than } \\
\text { every } 3-4 \text { days } \\
\text { to max tolerated } \\
\text { dose }\end{array}$ \\
\hline
\end{tabular}

-Anticipate extended prior authorization turnaround times with initial drug approval

-Complex prior authorizations due to varying dosages

-BID dosing of selexipag may be preferable over TID treprostinil -Successful transitions to-and-from

IV, SQ, inhaled, oral prostanoids

-Selexipag has fewer titration steps than treprostinil

-Goal is maximally tolerated dose that is effective regardless of dosage strength achieved

Treprostinil:

-Requires substantial caloric/protein intake with each dose

-Significant GI side effects, which limit ability to titrate dose

-Greater risk for medication-related error due to a higher number of titration increments, increased

frequency of titration, as well as, greater complexity of titration if titrating one dose at a time

\section{-Anti-diarrhea therapies:}

diphenoxylate/atropine, loperamide -Anti-nausea therapies:

promethazine, ondansetron,

prochlorperazine

-Pain management

\section{Dose titration tips}

-May need to slow up-titration to improve tolerability

tolerable

-Selexipag: if side effects persist, consider increasing PM dose first, then increasing AM dose once PM dose is well-tolerated

-if side effects persist, consider

taking with food or increasing

caloric intake and protein content

\begin{tabular}{|l|l|}
\hline \multicolumn{2}{|c|}{ Inhaled Prostanoids } \\
\hline \multicolumn{1}{|c|}{ Iloprost } & \multicolumn{1}{|c|}{ Treprostinil } \\
\hline $\begin{array}{l}\text { Starting dose: } \\
2.5 \text { mcg 6-9 }\end{array}$ & $\begin{array}{l}\text { Starting dose: } 3 \\
\text { breaths QID }\end{array}$ \\
\hline
\end{tabular}

times daily $\quad$ Titrate by 3

Titrate up to 5 breaths weekly

mcg 6-9 times up to 9 breaths

daily OID

-Anticipate extended prior authorization turnaround times with initial drug approval

-Potentially less out-of-pocket cost compared to oral prostanoid

therapy

-Must carry inhalation system for dosing

-High treatment burden: requires daily preparation, administration, and cleaning

\section{Treprostinil:}

-Can titrate by single breaths

-One ampule can provide 12 to 15

breaths for a higher dose if

necessary

-May be preferred if concomitant

underlying lung disease

-Cough may be mitigated by lozenges and frequent mouth rinsing

-Review inhalation technique: breaths are gentle, unlike customary inhalers

-Treprostinil: may need to slow uptitration to a single breath at a time to improve tolerability

\section{Epoprostenol and Treprostinil}

\section{Starting dose: $1-2 \mathrm{ng} / \mathrm{kg} / \mathrm{min}$}

Increase by $1-2 \mathrm{ng} / \mathrm{kg} / \mathrm{min}$ every $12-24$ hours while inpatient; as an outpatient, increase by $1-3 \mathrm{ng} / \mathrm{kg} / \mathrm{min}$ every $24-72$ hours with cartridge changes as tolerated to a therapeutic goal of at least $30-40 \mathrm{ng} / \mathrm{kg} / \mathrm{min}$

\begin{tabular}{|c|c|}
\hline Epoprostenol & Treprostinil \\
\hline $\begin{array}{l}\text { IV (+ diluent) } \\
\text {-Half life: } 3-5 \text { minutes } \\
\text {-Generic and branded Flolan }\end{array}$ & $\begin{array}{l}\text {-Half life: } 4 \text { hours (longer half life allows for } \\
\text { additional time to access care if therapy is } \\
\text { interrupted) }\end{array}$ \\
\hline
\end{tabular}
are only stable for up to 8 hours at room temperature following mixing (up to 24 hours with cold packs) -Branded Veletri is stable for longer periods at room temperature following mixing

-Premixed solution is available in some geographic areas at certain stable doses -Recommend tunneled line with dedicated single lumen -Take strict precautions (e.g. warnings signs, labeling the line, etc.) to avoid accidental bolus injection

-Significant risk of central line infection; impeccable central line care is paramount

\section{IV (+ diluent)}

-Generic available

-Requires mixing

Q (no diluent)

Site irritation is common; site pain

Premixed solution is may be intolerable available in some -Generic is available geographic areas for but SQ pump is patients on a stable dose of treprostinil - only, thereby limiting line with dedicated utility of generic single lumen therapy

-Take strict precautions (e.g. warnings signs,

labelling the line, etc.) to avoid accidental

bolus injection

-Significant risk of central line infection; impeccable central line care is paramount

mportant considerations before prescribing

-Confirm availability of a support person: requires a 2-person check system to maintain sterile fields, manage infusion pump, care for infusion site, and ensure successful, safe infusion therapy

-Consider home environment, social circumstances, patient's and support person's dexterity, and likelihood of compliance, especially in patients with a history of substance abuse

-Initiation involves intensive teaching of both the patient and the support person; both should demonstrate independence in preparing and administering parenteral therapy

-Recommend using IBW for consistent dosing weight throughout therapy -Local emergency rooms, EMS, and inpatient hospital units welcome educational sessions and materials, as well as available PH expertise, to assist in managing patients on parenteral prostanoid therapy

\section{-Anti-diarrhea therapies:}

diphenoxylate/atropine, loperamide

-Anti-nausea therapies:

promethazine, ondansetron, prochlorperazine

-Pain management:

acetaminophen often used

\section{SQ site pain managemen}

-Histamine blockers: loratadine (H1), famotidine (H2)

-Topical therapies: fluticasone nasal spray, lidocaine cream and patches, diclofenac gel, specialty topicals (commonly known as PLO gel)

-Use opioids sparingly, as few report effective pain relief

-May need to slow up-titration schedule for tolerability (e.g. increase weekly or every other week)

-Dry site placement is encouraged

-Recommend keeping sites for as long as tolerated (aim 4 to $6+$ weeks)

Fig. 1 Prostanoid prescribing and management considerations. EMS, emergency medical services; IBW, ideal body weight; PH, pulmonary hypertension; WHO-FC, World Health Organization Functional Class 


\section{Oral Prostanoids}

There are numerous challenges to both parenteral and inhaled prostanoid formulations, which require additional resources, time, and education for safe and effective use of these therapies. For these reasons, an oral formulation serves as an attractive alternative. Nearly 20 years after the introduction of IV epoprostenol, the FDA approved oral treprostinil diolamine in an extended release formulation [39]. However, treprostinil diolamine uptake in clinical practice has been limited, in large part due to mixed results in the literature. In the FREEDOM M trial, treprostinil monotherapy in treatment-naïve, WHO-FC II-III PAH patients significantly improved 6MWD [42]. Conversely, in patients already receiving background PAH therapies, oral treprostinil failed to show significant improvement in 6MWD or TTCW in both the FREEDOM C [40] and FREEDOM C2 [41] trials. In the FREEDOM C and FREEDOM C2 trials, approximately $45 \%$ and $40 \%$ of patients, respectively, were on both an ERA and PDE5i at baseline. More recently, in the 2019 FREEDOM-EV trial, oral treprostinil significantly decreased time to first clinical worsening event by $26 \%$ compared to placebo in patients who were recently diagnosed with PAH (median of 6.4 months) and on monotherapy PDE5i or ERA at baseline [43]. The treatment difference was driven by delayed disease progression. On the whole, the evidence for the use of oral treprostinil is conflicting, and its place in clinical practice remains unclear, particularly without any distinctive benefit in the contemporary setting, where upfront combination therapy is now the standard of care.

The recommended starting dose for treprostinil diolamine is $0.25 \mathrm{mg}$ twice daily or $0.125 \mathrm{mg}$ three times daily and is typically increased every 3-4 days as tolerated [39]. Three times daily dosing is preferred in order to avoid large swings in serum drug levels. A large peak:trough ratio may result in increased adverse effects and limit the max daily dose achieved. Furthermore, patients may also experience prolonged periods at low drug levels [69]. Common adverse effects include diarrhea, headache, nausea, flushing, jaw pain, fatigue, and myalgias $[39,70]$. Strategies to improve drug tolerability and cut down on the severity of dose-limiting side effects include [1] three times daily dosing; [2] dose titration in increments no greater than $0.125 \mathrm{mg}$, which can be initiated with one dose first (usually the evening dose); and [3] extending the intervals between dose titrations to allow patients more time to acclimate to the effects of the medication [69] (Fig. 1). The oral bioavailability of treprostinil diolamine is $\sim 17 \%$ and should be administered with a 250 -cal meal containing 30 $50 \%$ fat to enhance drug absorption [71]. As with other PAHspecific therapies, abrupt discontinuation of treatment should be avoided. The dose may be reduced in increments of $0.5-$ $1 \mathrm{mg}$ per day, with consideration for tablet strength, as tablets may not be cut or crushed [39].
The other orally available agent targeting the $\mathrm{PGI}_{2}$ pathway, selexipag, received FDA approval in 2015. Selexipag is a selective prostacyclin receptor (IP receptor) agonist [37, 72] recommended for use in WHO-FC II-III PAH patients [57]. In the 2015 GRIPHON trial, the primary endpoint of morbidity and mortality occurred in significantly fewer patients on selexipag compared to those in the placebo arm. Study patients were predominantly WHO-FC II-III and on concomitant ERA and/or PDE5i therapy. The treatment effect was driven primarily by disease progression and hospitalization as a result of worsening PAH. 6MWD was also notably improved in the selexipag group. However, selexipag did not significantly reduce all-cause mortality [38].

The starting dose of selexipag is $200 \mathrm{mcg}$ twice daily. This is typically increased by $200 \mathrm{mcg}$ twice daily at weekly intervals to the highest dose tolerated by the patient up to a maximum dose of $1600 \mathrm{mcg}$ twice daily. Common adverse effects include headache, diarrhea, nausea, flu-like symptoms, and flushing [37]. These side effects typically subside with time and may require increasingly longer periods of adjustment as the doses get higher. A single-dose step-up method may also be implemented for patients experiencing difficulty with dose titrations, where the evening dose is increased first before increasing the morning dose a week later. The expectation for maximally tolerated doses should not be that side effects subside completely, but rather the dose at which the patient experiences side effects that are manageable. Side effect management strategies vary by center (Fig. 1). Once the side effects become intolerable or unmanageable, the dose is decreased by $200 \mathrm{mcg}$ twice daily and parked. This dosing strategy stems from the GRIPHON trial, which saw all maximally tolerated doses demonstrate similar efficacy for the composite primary endpoint.

Ralinepag is another selective IP receptor agonist currently undergoing phase 3 clinical trials (https://clinicaltrials.gov/ ct2/show/NCT03626688). In the phase 2 clinical trial, ralinepag significantly reduced PVR in PAH patients on background PAH-specific therapies [73]. The extendedrelease formulation being tested in the ongoing phase 3 trial provides the advantage of once daily dosing. Phase 3 study results are expected in 2021-2022 (https://clinicaltrials.gov/ ct2/show/NCT03626688).

\section{Combination Therapy}

As our understanding of PAH further develops, coupled with expanding research, development, and clinical experience with novel PAH-specific therapies, the paradigm for the optimal management of PAH has shifted in recent years. Combination therapy, targeting the NO, ET-1, and $\mathrm{PGI}_{2}$ pathways, has emerged as the contemporary standard of care in treatment of PAH patients. Historically, combination therapy was implemented in a sequential method based on baseline 
and subsequent $\mathrm{FC}$, as well as hemodynamic assessments. The AMBITION trial, published in 2015, was a randomized, controlled trial in WHO-FC II-III PAH, treatment naïve patients comparing combination therapy with tadalafil $40 \mathrm{mg}$ daily and ambrisentan $10 \mathrm{mg}$ daily versus tadalafil or ambrisentan monotherapy. The primary endpoint was the first event of clinical failure, time to clinical failure (TTCF), defined as the first occurrence of a composite of death, hospitalization for worsening PAH, disease progression, or unsatisfactory long-term clinical response. Patients started on combination therapy had a significantly longer TTCF (HR 0.50, 95\% CI: $0.35-0.72 ; p<0.001)$ [20]. The 2015 European Society of Cardiology/European Respiratory Society (ESC/ ERS) guidelines assigned class I recommendations for combination therapy with the following: macitentan and sildenafil (based on the SERAPHIN trial) [31], riociguat and bosentan (based on the PATENT-1 trial) [34], and selexipag and PDE5i or ERA therapy (based on the GRIPHON trial) [38]. Other dual therapy combinations were given a lower level of evidence recommendation [57].

However, despite a decrease in TTCW, many patients continue to experience worsening symptoms, clinical deterioration, and limited functional status. This has naturally given way to exploring the effects of triple combination therapy on patient outcomes. Three main studies have looked at triple therapy. The first trial, a small pilot study of 19 patients, initiated combination therapy with IV epoprostenol, bosentan, and sildenafil. Overall, the patients had improvements in 6MWD, hemodynamics, FC, and survival [74]. Secondly, the GRIPHON trial demonstrated benefit in adding on selexipag to ERA and PDE5i background therapy [38]. In the GRIPHON trial, $14.7 \%$ of patients were on PDE5i monotherapy, $32.4 \%$ on ERA monotherapy, and $32.5 \%$ on both ERA and PDE5i therapy. Within the prespecified subgroup analysis, the benefit in the primary outcome was still present within the dual therapy group [38]. Thirdly, the TRITON trial provides more information regarding combination therapy (https://clinicaltrials. gov/ct2/show/NCT02558231). The TRITON study is a multicenter, double-blind, placebo-controlled, phase $3 \mathrm{~b}$ study with newly diagnosed, treatment-naïve PAH patients randomized to upfront triple or initial double therapy. Macitentan and tadalafil were initiated at randomization, and selexipag or placebo was added at day 15 (and subsequently uptitrated until week 12). The primary endpoint was change in PVR at week 26. Initial triple and initial double therapy reduced PVR by $54 \%$ and $52 \%$, respectively, with no difference between the groups. In addition, both groups saw improvement in 6MWD and NT-proBNP, as well as no worsening in FC, with no difference between groups. Discontinuation rates due to adverse effects were similar between the initial triple and initial dual combination groups (https://www. atsjournals.org/doi/abs/10.1164/ajrccm-conference.2020. 201.1_MeetingAbstracts.A2928). This raises concern about the role and value of upfront initial triple combination therapy in Group $1 \mathrm{PAH}$.

As the body of evidence for combination therapy grows, it is important to consider individualized strategies to achieve adequate combination therapies while minimizing adverse side effects that may lead to therapy discontinuation (Fig. 1). Some of these strategies include staggered therapy initiation and dose titrations, frequent monitoring, and aggressive management of adverse drug reactions [75]. It is essential for clinicians to adapt and tailor recommendations as more data becomes available and to determine the optimal approach to the pharmacologic management of PAH.

\section{Personalizing Pulmonary Arterial Hypertension Therapies}

When determining the optimal therapeutic approach for PAH patients, there are several best practice guidelines from the ESC/ERS, CHEST, and the World Symposium of Pulmonary Hypertension (WSPH) [6, 57, 76]. Risk is routinely assessed through ECS/ERS and REVEAL 2.0 risk calculators with therapies tailored accordingly [57, 77]. There are currently 14 FDA-approved therapies in the USA, and therapeutic changes may be appropriate months to years after initiation to accommodate clinical status and patient-specific needs.

Once an accurate assessment of all PH risks has been completed, appropriate diagnostic tests have been performed, and WHO Group 1 PAH confirmed, a determination should be made as to whether the patient is high, intermediate, or low risk (Figs. 2 and 3). The ESC/ERS and REVEAL 2.0 risk categorization guides are frequently used to guide initial therapy class choices [57, 77]. These risk assessments include clinical evaluation for signs of right heart failure, WHO-FC assessment, laboratory values (viz., NT-proBNP levels), imaging findings, and hemodynamics, in addition to the etiology of PAH.

For a new diagnosis of PAH, the 6th WSPH recommends upfront dual combination therapy with an ERA and PDE5i [76]. Although preferable, simultaneous initiation of an ERA and PDE5i can be challenging. Many programs initiate a PDE5i, and within a few days or weeks, rapidly initiate an ERA if upfront dual combination therapy is not feasible (Fig. 3). Follow-up visits should be scheduled within weeks of therapy initiation to discuss any side effects, as well as provide an opportunity to review the disease state, questions, 
High Risk

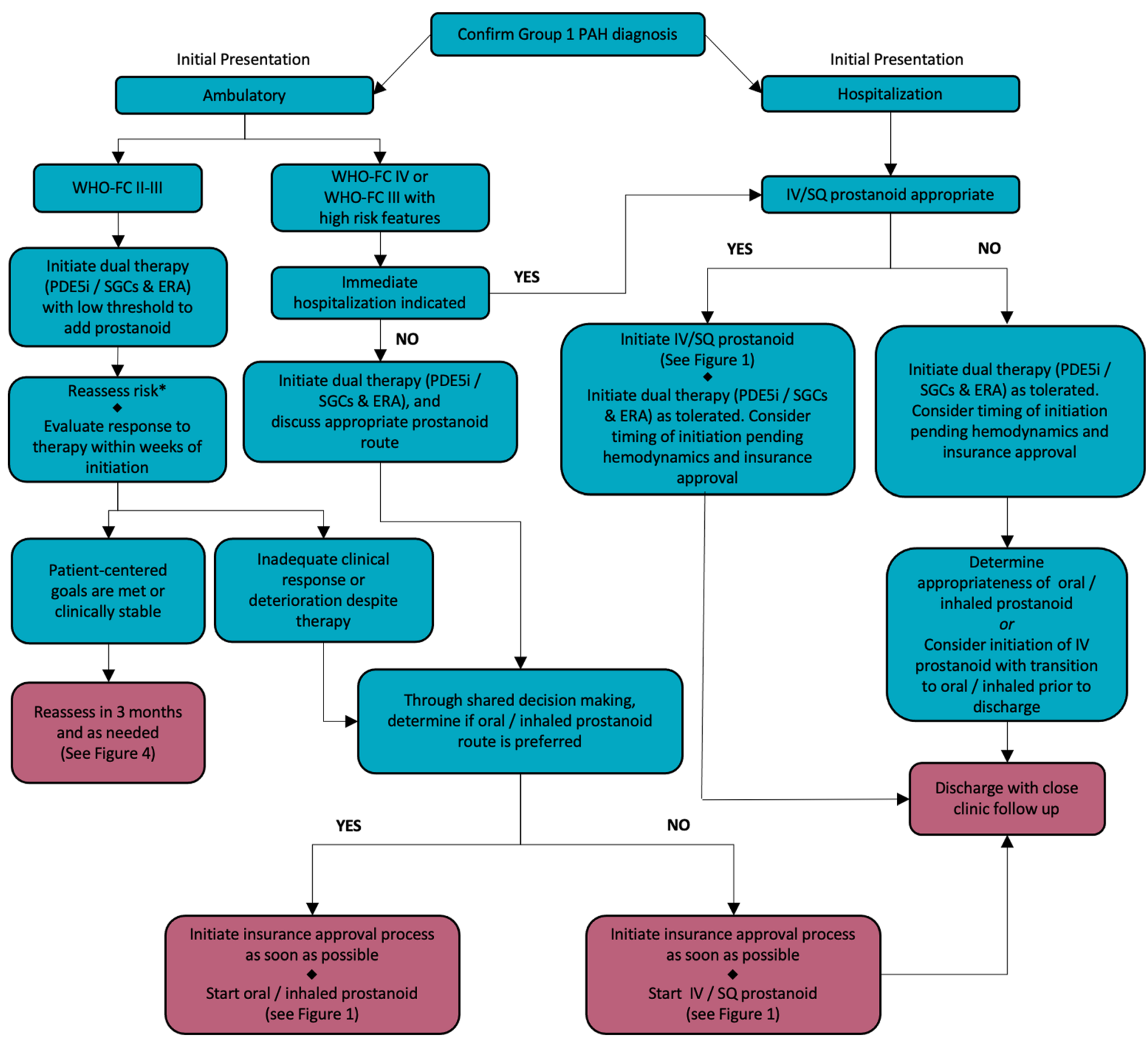

Fig. 2 Management of high-risk PAH patients. bid, twice a day; ERA, endothelin receptor antagonist; PAH, pulmonary arterial hypertension; PDE5i, phosphodiesterase 5 inhibitor; $\mathrm{PH}$, pulmonary hypertension;

PRN, as needed; SGCs, soluble guanylate cyclase stimulator; tid, three times a day; qid, four times a day; WHO-FC, World Health Organization Functional Class

management of comorbidities, and other supportive measures such as oxygen and diuretics. REMS considerations, if applicable, should also be reviewed. Separating the initiation of a PDE5i and an ERA, even by a few days, often not only helps to facilitate insurance approval of the ERA but also helps to identify adverse effects from a specific therapy. If a PDE5i is not tolerated or is contraindicated, riociguat is preferred and will require additional time for titration. In addition, it may be reasonable to switch from a PDE5i to riociguat in patients who remain at intermediate risk based on the REPLACE trial (Fig. 3) (https:// pharmaceutical-business-review.com/news/bayeradempas-phase-4-trial/).

In a low-to-intermediate risk patient on combination therapy, reassessment within 3 months is preferred to evaluate goals, functional response to therapy, and possible need for prostacyclin therapy (Fig. 4). It is important to continually reassess diagnosis and other risk factors for $\mathrm{PH}$, ensure comorbidities are optimally managed, and review medication 


\section{Low / Intermediate Risk}

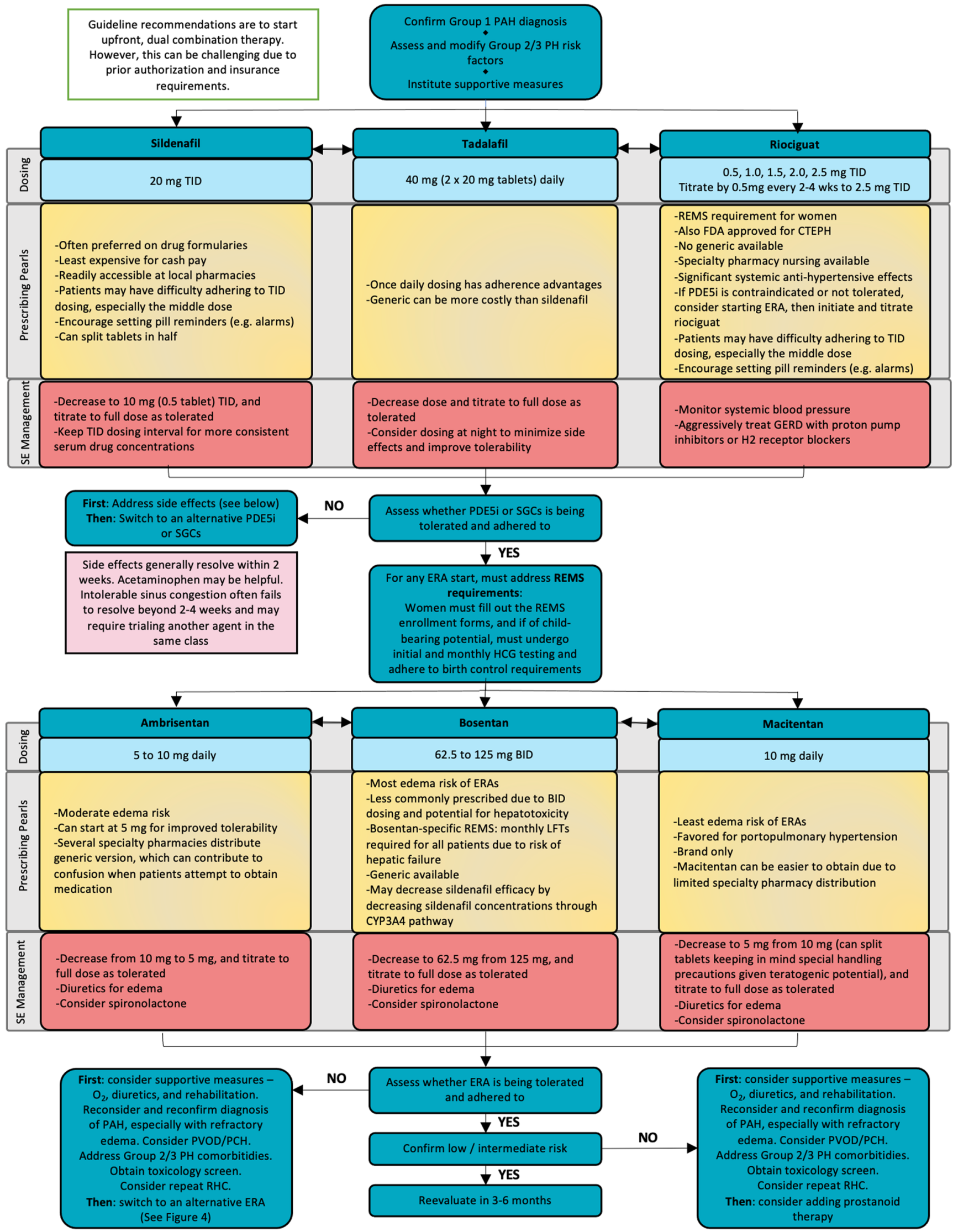


Fig. 3 Management of low-intermediate risk PAH patients. bid, twice a day; ERA, endothelin receptor antagonist; FDA, Food and Drug Administration; GERD, gastro-esophageal reflux disease; PAH, pulmonary arterial hypertension; PDE5i, phosphodiesterase 5 inhibitor; $\mathrm{PH}$, pulmonary hypertension; PVOD, pulmonary veno-occlusive disease; REMS, risk evaluation and mitigation strategy; RHC, right heart catheterization; SGCs, soluble guanylate cyclase stimulator; tid, three times a day; WHO-FC, World Health Organization Functional Class

compliance, especially if patients lack subjective or objective improvement on dual therapy (Table 4). In a high risk but stable patient, as often indicated by first visit in an ambulatory setting as opposed to the hospital, dual combination therapy is rapidly initiated. Using shared decision-making considers the preferred route of prostanoid therapy early on in the care of the patient. When initiation of a parenteral prostanoid is indicated, prescribing considerations include geographic distance from their PAH care center, social circumstances including availability of support person, patient dexterity, and risk profile for infection.

Patient tolerability, both physically and financially, should be considered. In the USA, we remain subject to insurance formularies, hospital availability, and patient cost sharing. Clinicians play an important role in advocating on behalf of patients for insurance approval of PAH-specific therapies (Table 5). However, this requires dedication of additional time and resources and more importantly, can delay time to

Table 4 Special Considerations in Treatment Selection of PAH

Continually reassessing WHO Group 1 PAH vs. other WHO Group PH risks and management remains important to patient-centered care (especially in those with overlapping cardiac and/or lung disease).

Monotherapy may be appropriate for some.

Patients should be counseled that PAH-specific therapies oftentimes do no immediately improve symptoms or functional status and may take weeks or months to notice improvement.

Oxygen, diuretics, and other supportive therapies remain important in reaching low risk status.

Vasoreactivity should always be assessed when appropriate (i.e., idiopathic, familial, or drug/toxin-induced $\mathrm{PH}$ ), and CCB therapy initiated as indicated.

A more convenient therapy does not always equate to improved tolerability. Side effects of one medication within a drug class may not be as frequent or severe with another medication within the same therapeutic class.

Connective tissue disease patients often have overlapping interstitial lung disease. Use extra caution and monitor closely for side effects and deterioration with vasodilators.

Toxin-induced patients, particularly those currently using methamphetamines, may struggle with medication compliance and adherence to REMS requirements.

Initiation of medications with REMS requirements need to be carefully considered, particularly in women of child-bearing potential and the ability to reliably perform monthly pregnancy testing. initiation of therapy for up to a month or more. Each patient case should be individualized according to the risk assessment, medication preference (taking into consideration comorbidities), and potential cost hurdles based on experience with insurance formularies.

\section{Interventional Strategies for Pulmonary Arterial Hypertension}

While pharmacotherapy remains the cornerstone of treatment, PAH remains a progressive, fatal disease with a fair amount of heterogeneity in response to pharmacotherapy [78]. Several non-pharmacologic options have been explored as adjunct therapies and have shown improvement in hemodynamics and quality of life in high risk PAH populations in small clinical experiences [79-82]. However, given the lack of data surrounding these techniques, non-pharmacologic therapies discussed in this section are largely considered palliative or a bridge to transplantation at this point.

\section{Atrial Septostomy}

Balloon atrial septostomy involves the creation of a rightto-left shunt using percutaneous balloon dilations across the interatrial septum, reducing right ventricular pressure and volume. This consequentially increases cardiac output which augments systemic oxygen transport despite decreasing systemic oxygen saturation $[80,83]$. The idea behind creation of an interatrial shunt dates back to the 1980s when patients with patent foramen ovale and $\mathrm{PAH}$ with resultant right-to-left shunting were noted to have improved survival compared to those without shunting [84]. Decades following this discovery, the precise role for atrial septostomy remains uncertain, and data regarding its use largely comes from small case series and case reports. The most recent data available suggests a hemodynamic and symptomatic benefit in patients with WHO-FC IV symptoms due to right sided heart failure despite optimal pharmacologic therapy $[80,82,85]$. In this patient population, patients were noted to have increased cardiac index, decreased right atrial pressure, and improvement in 6MWD following atrial septostomy. However, the impact of atrial septostomy on long-term survival has not been established, and current guidelines recommend considering atrial septostomy only as a palliative or bridging measure in experienced centers [86]. Furthermore, baseline right atrial pressures of $>20 \mathrm{mmHg}$ or resting arterial oxygen saturations $<85 \%$ are contraindications to atrial septostomy due to the hemodynamic alterations that occur following the procedure. 


\section{Reevaluation Following Initiation of Therapy}
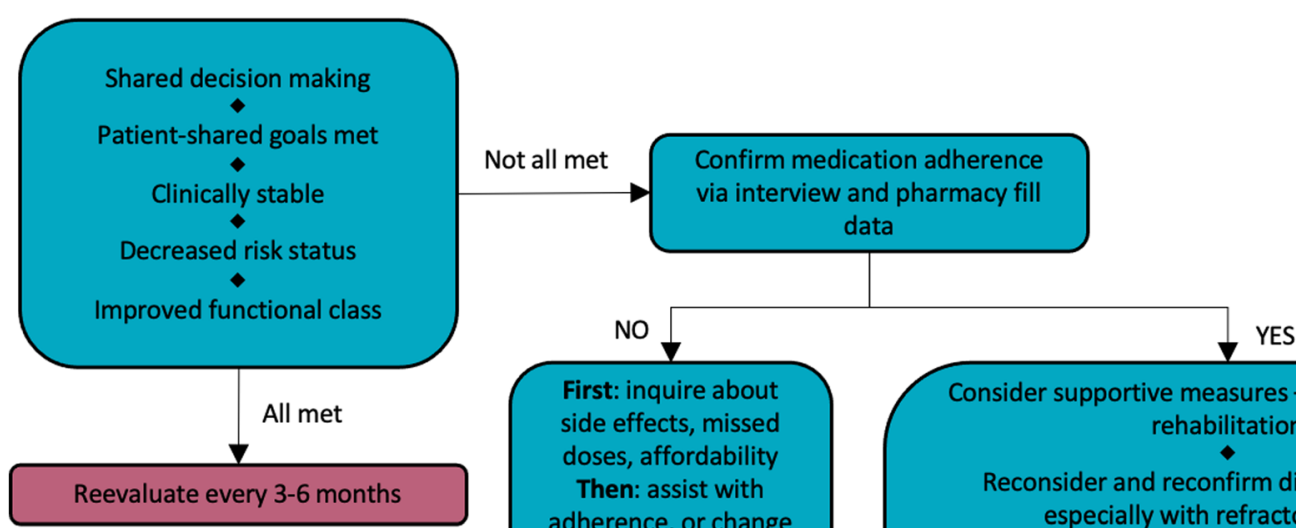

First: inquire about side effects, missed doses, affordability

Then: assist with adherence, or change agents and reevaluate

Consider supportive measures $-\mathrm{O}_{2}$, diuretics, and rehabilitation

Reconsider and reconfirm diagnosis of $\mathrm{PAH}$, especially with refractory edema

Consider PVOD / PCH

Address Group 2/3 PH comorbidities

Obtain toxicology screen

Consider repeat RHC

-

Determine if appropriate to transition from PDE5i to SGCs

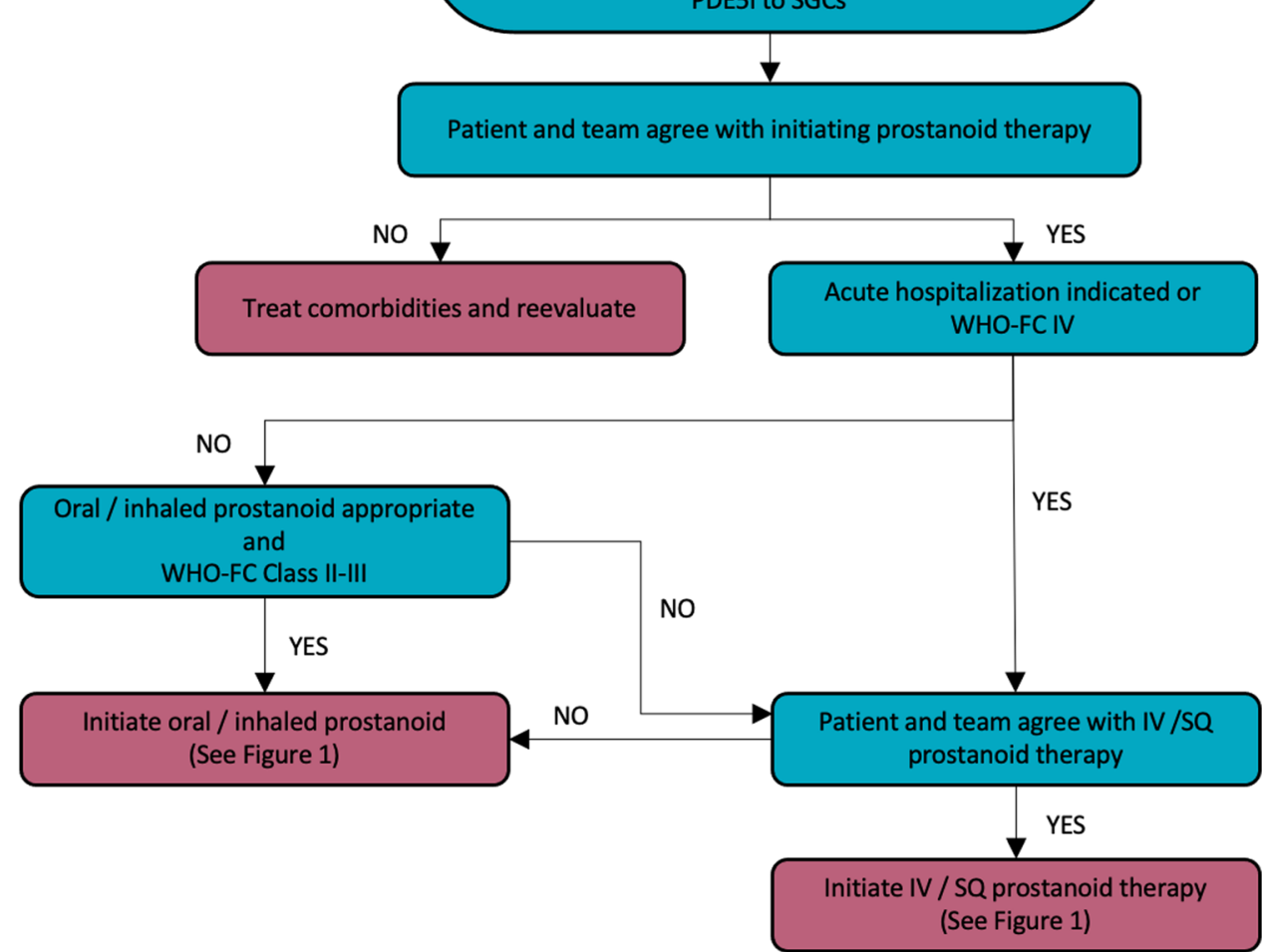

Fig. 4 Reevaluation of patients with PAH after initiation of therapy. PAH, pulmonary arterial hypertension; PH, pulmonary hypertension; PVOD, pulmonary veno-occlusive disease; RHC, right heart catheterization; WHO-FC, World Health Organization Functional Class

\section{Potts Anastomosis}

Initially described decades ago for the management of certain congenital heart diseases, a Potts anastomosis/shunt involves a surgical anastomosis of the left pulmonary artery to the descending aorta via a left thoracotomy. More recently, a technique for transcatheter Potts shunt creation was also described, though data regarding this approach is sparse [87]. A Potts shunt creates a right-to-left shunt that theoretically avoids arterial oxygen desaturation above the level of the anastomosis, sparing cerebral and coronary circulation. Thus far, the most robust evidence for Potts shunting as an adjunctive treatment in PAH is in children. A small case series of 24 children undergoing surgical Potts anastomosis (ages 1.5-17 years) 
Table 5 Financial considerations that impact treatment options in $\mathrm{PAH}$

Insurance specific

- Prior authorization is required in most cases. A comprehensive progress note facilitates faster approvals. The progress note should include:

- WHO Group

- Functional Class

- Current PAH therapy regimen

- PAH therapies tried and failed with approximate dates

- Right heart catheterization results including vasoreactivity assessment

- Rationale for PAH-specific therapy if risk factors for other WHO Group $\mathrm{PH}$ exist

- Therapies often may only be filled at a specific specialty pharmacy or may be less expensive at payer-preferred pharmacies which can be less convenient

Medication cost

- Medication price is often not readily available to prescribers and may first require prior authorization and then coordination with pharmacy and/or insurance to assess affordability

- Generics may cost more out-of-pocket if a copay card is available through the branded drug manufacturer

- Copay cards offered by drug manufacturers are restricted to commercial patients only (cannot be used with Medicare, Medicaid, Tricare, etc.)

- Encourage patient to consider total yearly out-of-pocket costs as monthly expenses may fluctuate throughout the year and satisfy various insurance structures including:

- Annual deductibles

- Maximum out-of-pocket for commercial insurance

- Coverage gap (i.e., donut hole) and catastrophic coverage for Medicare

Patient assistance (primarily based on financial need)

- Additional financial support may be available and requires patient effort and initiative. Often entails formal income and residency verification. Examples include:

- Non-profit grants primarily for Medicare patients

- Manufacturer assistance for branded therapies if grants are not available

- Specialty pharmacy assistance in select cases (patient must ask pharmacy)

- Uninsured patients or those who have received an insurance denial and subsequent appeal denial for a branded therapy for an FDA-approved indication may qualify for patient assistance through the manufacturer at zero cost

with drug-refractory PAH showed improvement in WHO-FC, 6MWD, and NT-proBNP levels with no further worsening of right ventricular function (median follow-up of 2.1 years) in the 21 patients who survived the procedure [88]. While early experience with this technique is promising in small case series, further understanding and refinement of patient selection criteria are warranted to establish the role of Potts shunting as a therapeutic modality in PAH.

\section{Pulmonary Artery Denervation}

Similar to renal denervation for systemic hypertension, modification of sympathetic pulmonary innervation has been proposed as a potential target for pulmonary arterial hypertension therapy. While results from animal models demonstrating the role of sympathetic tone in pathogenesis and as a potential target for intervention have been promising, relevance to human disease remains unproven $[89,90]$. A first-in-man, single center study of 13 patients undergoing pulmonary arterial denervation demonstrated significant reduction in mean PAP, NT-proBNP, and improvement in 6MWD, pulmonary arterial compliance, and functional capacity compared to a control group at 3 months [91]. Additionally, no major complications of the procedure were reported. In the multicenter, open-label TROPHY trial, intravascular ultrasound pulmonary artery denervation decreased PVR and was associated with an improved 6MWD [92]. While these results are encouraging, further investigation and confirmation of these findings are required before this strategy can be adopted into clinical practice.

\section{Atrial Septal Defect Closure}

Atrial septal defects (ASDs) are among the most common of congenital heart diseases, and PAH has been associated with ASDs in 4-34\% of patients [93, 94]. Based on the most 2018 AHA/ACC guideline for the management of adults with congenital heart disease, closure of an ASD is currently indicated to reduce right atrial and right ventricular pressure/volume if there is evidence of right-sided enlargement and net left-to-right shunting with pulmonary-systemic blood flow ratio (Qp:Qs) $\geq 1.5$, provided the PAP is less than $50 \%$ of systemic blood pressure and PVR is less than one-third of the systemic vascular resistance (Class I, Level of Evidence B) [95]. Closure of an ASD in adults with PAP greater than two-thirds systemic pressure, PVR greater than two-thirds systemic, or net right-toleft shunting is not recommended (Class III, level of evidence C) [95]. However, there are no set guidelines regarding atrial septal defect closure in the presence of net left-to-right shunting with PAP or PVR between one-half and two-thirds systemic pressure or resistance [95]. Despite the lack of conclusive data, pulmonary vasodilator testing is generally recommended in this scenario for patients with a baseline pulmonary vascular resistance index (PVRI) of 6-9 WU*m2. A 20\% decrease in PVR, a 20\% decrease in pulmonary vascular resistance:systemic vascular resistance (PVR:SVR) ratio, a final PVRI $<6 \mathrm{WU} * \mathrm{~m} 2$, and final PVR:SVR ratio $<33 \%$ with vasodilator challenge likely indicate a favorable response after atrial septal defect closure, though this is largely based on small case series and expert consensus [96].

\section{Surgical Management of Pulmonary Arterial Hypertension}

\section{Indications for Lung Transplant}

While medical therapies for PAH have made great strides in recent years, lung transplantation remains an important therapy for patients with severe disease refractory to medical therapy. Although transplantation for PAH is a relatively rare indication ( $\sim 5 \%$ of all lung transplants) compared to COPD 
or interstitial lung disease, referral is appropriate when the patient's predicted 2-3-year survival is estimated to be $<$ $50 \%$ [57]. Perioperative risk is minimized with early referral before severe cardiac dysfunction and hepatic congestion develop. Widely accepted criteria for the referral for transplant evaluation consist of the following:

- WHO-FC III of IV symptoms despite maximal medical therapy

- A markedly low $(<350 \mathrm{~m})$ or declining $6 \mathrm{MWD}$

- Cardiac index of $<2 \mathrm{~L} / \mathrm{min} / \mathrm{m}^{2}$

- Central venous pressure $\geq 15 \mathrm{mmHg}$

Listing for lung transplantation is appropriate with deterioration of functional status and hemodynamics. Not all patients with $\mathrm{PAH}$, however, are candidates for transplantation, and the usual contraindications (active/recent malignancy, substance abuse, poor social support, non-adherence) still apply. Since 2005, organs in the USA have been allocated under a new system called the Lung Allocation Score, or LAS. It serves as a severity of illness score ranging from 0 (well) to 100 (ill). The LAS weighs the probability of death in 1 year without transplant against the probability of death 1 year posttransplant. The purpose of implementing the LAS was to decrease deaths on the wait list, and it lowered wait-list mortality for all etiologies of lung failure except PAH. These changes relatively disadvantaged patients with PAH from getting an organ with some evidence of increased wait-list mortality $[97,98]$. This led to LAS exceptions relating to evidence of worse prognosis, specifically cardiac dysfunction (elevated central venous pressure and/or low cardiac index) [98].

\section{Type of Transplant and Results}

The overwhelming majority of patients receiving lung transplantation for PAH receive bilateral lung transplants (BLT) rather than single lung transplants (SLT), although the evidence to support this practice is fairly weak. Proponents of SLT cite the benefits of lower perioperative morbidity, improved graft function, and more equitable organ allocation, while proponents for BLT argue for possible improved longterm survival, and patients are easier to manage in both the early and late term due to less V/Q mismatching. Despite the controversy, the overwhelming majority of patients (91\%) with PAH receive BLT with good results [99]. Heart-lung transplantation is an option for patients with end-stage PAH and severe cardiac dysfunction. It is usually reserved for patients with PAH related to congenital heart disease and represents $<2 \%$ of lung transplants [99]. In general, patients with PAH have higher perioperative risks, and conditional survival (at 1 year) is superior to COPD and interstitial lung disease.

\section{Future Directions in Pulmonary Arterial Hypertension Management}

As previously stated, currently available therapies for treating PAH target endothelial cell dysregulation and smooth muscle cell tone and proliferation through three mechanistic pathways: the ET-1 pathway, the NO pathway, and the $\mathrm{PGI}_{2}$ pathway [1, 100]. However, pathologic mechanisms leading to the characteristic histologic findings and dysfunctional pulmonary vascular endothelium in PAH are complex and include dysregulated inflammation with immune activation, oxidative stress, an imbalance of proliferative and anti-proliferative signaling, growth factor activation, dysfunctional metabolism, and altered hormonal signaling $[101,102]$. Recent efforts have focused on exploiting the multiple mechanisms leading to pulmonary vascular remodeling seen in PAH to develop novel therapeutics. Various pathways for target include suppressing inflammation and modulating the immune response, altering oxidant stress mechanisms, restoring the balance between pro-proliferative and antiproliferative signaling, and targeting growth factor signaling pathways pertinent to BMPR2 regulation [101, 103, 104].

Sustained inflammation and immune activation lead to increased cytokine and chemokine production with subsequent perivascular infiltration of macrophages, granulocytes, mast cells, dendritic cells, B and T lymphocytes, and natural killer T cells [101]. There is evidence that the presence of soluble factors and cell surface molecules (i.e., IL-1, IL- 6 , TNF- $\alpha$, CRP, and MCP-1) and activation of signaling pathways play critical roles in promoting vascular remodeling, portend a worse prognosis, and may serve as biomarkers of disease progression or, importantly, future therapeutic options [105-110]. Recent studies have examined anakinra and tocilizumab, IL-1 and IL-6 receptor antagonists, respectively, for their use in PAH. The safety and feasibility of anakinra was investigated in a small, single-arm open label study [111]. Although the study was not designed to show improvement in clinical or functional outcomes, the authors were able to demonstrate nonsignificant improvements in clinical heart failure symptoms, lower IL-6 levels, and an inverse relationship between high sensitivity C-reactive protein levels and peak oxygen consumption. Tocilizumab was also shown to be a safe and feasible treatment option in $\mathrm{PAH}$ patients and demonstrated reduced C-reactive protein levels but failed to show a treatment effect in any of the measured clinical endpoints in a small exploratory open-label study [112]. These authors were able to provide clear proof of principle, safety, and feasibility data that support conducting future studies with a focus on clinically meaningful endpoints. Plasmablasts in idiopathic PAH have shown clonality similar to that observed in autoimmune diseases, and the CD-20 antibody, rituximab, has been studied for safety and efficacy of B cell depletion in systemic sclerosis associated-PAH; the safety profile was promising, and there were trends toward clinical improvements $[113,114]$. 
Mitochondrial generation of reactive oxygen species have been implicated in the development of PAH; inhibition of oxidative stress mechanisms has been proposed to attenuate pulmonary vascular remodeling seen in PAH $[115,116]$. Bardoxalone methyl activates Nrf2, a transcription factor that regulates the expression of antioxidant proteins and suppresses the activation of the pro-inflammatory NFKB pathway, and has shown promising results. In the multicenter, phase 2 LARIAT trial, patients with PAH on stable background therapy and WHO-FC II or III were assigned to bardoxalone methyl or placebo (https://clinicaltrials.gov/ct2/ show/NCT02036970). After 16 weeks of therapy, there was a significant improvement 6MWD in the treatment group as compared to the placebo group. The follow-up CATALYST and RANGER were discontinued during the COVID19 pandemic, and it was noted that bardoxalone was unlikely to meet its primary endpoint in the study (6MWD) (https:// clinicaltrials.gov/ct2/show/NCT02657356, https:// clinicaltrials.gov/ct2/show/NCT03068130, https:// pulmonaryhypertensionnews.com/2020/04/01/reata-stopspah-bardoxolone-trials-amid-covid-19-concerns/).

Impaired BMPR2 signaling is the most common genetic mechanism implicated in PAH and contributes to the development of pulmonary vascular disease through exaggerated TGF- $\beta$ signaling [117]. Because the BMPR2 receptor is a TGF- $\beta$ receptor subtype, targeting TGF- $\beta$ signaling with sotatercept, an activin receptor type $2 \mathrm{~A}$ fusion protein that acts as a ligand trap to competitively bind and neutralize TGF- $\beta$ ligands, is an exciting therapeutic prospect that attenuates PAH through reversing pulmonary artery remodeling, improving RV geometry, and restoring RV function in one preclinical model [118-120]. In the recently completed PULSAR trial, 106 patients with PAH on baseline therapies were treated with sotatercept or placebo (https://clinicaltrials.gov/ct2/ show/NCT03496207). Preliminary results indicate that after 6 weeks, there were improvements in right heart strain, exercise capacity, and a statistically significant reduction in PVR compared to placebo. The SPECTRA study is underway to examine the effects of sotatercept in adults with PAH and WHO-FC III symptoms (https://clinicaltrials.gov/ ct2/show/NCT03738150).

Modification of abnormal growth factor signaling in $\mathrm{PAH}$ is an area of active interest; tyrosine kinase inhibitors have shown mixed results in the treatment of PAH [103]. Imatinib demonstrated an improvement in exercise capacity and hemodynamics in the IMPRES trial but disappointingly had serious adverse events (subdural hemorrhage in patients receiving vitamin $\mathrm{K}$ antagonists) that prevented further use in the treatment of PAH [121, 122]. GB002 is an inhaled nonselective inhibitor of platelet-derived growth factor receptor- $\alpha$ and $-\beta$ that showed a reduced right ventricular systolic pressure and mean PAP, as well as reduced pulmonary arteriolar muscularization, restoration of BMPR2 signaling, and reduced NT-proBNP and cytokine levels in GB002-treated animals [123]. A phase 1 trial to investigate safety, pharmacokinetics, and pharmacodynamics of GB002 in patients with PAH is currently underway (https://clinicaltrials.gov/ct2/ show/NCT03926793). Given the wide range of possibilities for developing novel therapies that modulate underlying pathobiological mechanisms underpinning this disease, future researchers must collaborate to prioritize pre-clinical and clinical studies of new therapeutics.

\section{The Unmet Need of Group 2 and Group 3 PH}

More than $75 \%$ of all cases of $\mathrm{PH}$ are attributed to left heart disease or chronic lung diseases $[124,125]$. Despite the fact that $\mathrm{PAH}$ only accounts for $3 \%$ of all cases of $\mathrm{PH}$, significant efforts to understand the pathologic mechanisms underpinning $\mathrm{PAH}$ have been undertaken, which have led to the development of investigational novel therapies targeting implicated pathogenic pathways [103]. There is much need for a similar approach to $\mathrm{PH}$ in left heart disease and chronic lung disease-associated $\mathrm{PH}$.

Pulmonary hypertension in left heart disease and chronic lung disease-associated pulmonary hypertension encompass heterogeneous groups of multiple diseases that portend a poor prognosis [126, 127]. Pulmonary hypertension in left heart disease includes HFrEF, HFpEF, valvular heart disease, and heart disease resulting from chronic arrhythmias [128]. The traditional thinking is that $\mathrm{PH}$ in left heart disease results from passive pulmonary vascular congestion related to increased left-sided filling pressures (defined hemodynamically as isolated post-capillary PH with mean PAP $>20 \mathrm{mmHg}$, pulmonary arterial wedge pressure (PAWP) $>15 \mathrm{mmHg}$, and a PVR $<3 \mathrm{WU})$. However, in some instances, the elevated left-sided pressures do not completely account for remodeling that may develop over time and thus lead to combined pre- and postcapillary PH (defined hemodynamically as mean PAP > $20 \mathrm{mmHg}$, PAWP $>15 \mathrm{mmHg}$, and a PVR $\geq 3 \mathrm{WU}$ that resembles the "pulmonary vascular phenotype" of PAH (with mean PAP $>20 \mathrm{mmHg}$, PAWP $\leq 15 \mathrm{mmHg}$, and a PVR $\geq 3$ WU) [128]. Chronic lung disease-associated $\mathrm{PH}$ occurs most commonly in COPD and interstitial lung diseases and although is defined by the same hemodynamic properties as PAH (pre-capillary PH or a "pulmonary vascular phenotype"), it represents independent complex and multifactorial pathologic processes [129]. It is not surprising then that defining these groups solely based on strict hemodynamic definitions is problematic. To date, most studies using currently available advanced therapies (i.e., pulmonary vasodilators) in $\mathrm{PH}$ in left heart disease have focused on patients with HFrEF and isolated post-capillary PH; all such studies have been negative, or proved to be harmful [126, 128]. Studies of pulmonary vasodilators in chronic lung disease-associated $\mathrm{PH}$ have been limited to patients with COPD or idiopathic pulmonary fibrosis, only one of the many subtypes of fibrosing lung 
diseases. While mostly disappointing, recent studies using inhaled NO [130] and inhaled treprostinil showed promising results in patients with idiopathic pulmonary fibrosis and any form of interstitial lung disease, respectively (https:// clinicaltrials.gov/ct2/show/NCT02630316).

If we are to advance our understanding of the pathophysiology of and treatment options for PH in left heart disease and chronic lung disease-associated $\mathrm{PH}$, we need to focus attention on defining clinical and hemodynamic sub-phenotypes, discovering disease-specific biomarkers, establishing scoring and risk stratification systems, and developing carefully controlled trials that do not exclude disease subtypes (such as HFpEF, left heart disease with combined pre- and postcapillary $\mathrm{PH}$, undefined subtypes of idiopathic interstitial pneumonias, or other chronic lung diseases) [126, 129]. Improved understanding and effective treatments of WHO Groups 2 and 3 PH must include a multimodality approach that combines currently available disease-specific standard of care therapies with novel therapies targeting the underlying pathology that leads to $\mathrm{PH}$.

\section{Summary}

The management of PAH is increasingly complex. Specialized centers are best suited to provide the comprehensive care management required. With the growing number of therapeutics clinically available, intimate knowledge of pharmacology and side effects is integral to providing optimal care for this vulnerable and high-risk patient population. In addition, patients with $\mathrm{PAH}$ often present with multiple comorbidities further complicating management or even call to question the type of $\mathrm{PH}$. Interventional strategies remain largely palliative in nature or serve as a bridge to transplantation.

Funding Dr. Ryan and his research is supported by funding from The Reagan Corporation, The Gordon Family, and The Cushman Family.

\section{Compliance with Ethical Standards}

Conflict of Interest Irene Pan, John Dechand, Josh Jacobs, Tara Jones, Stephen McKellar, Emily Beck and Nathan Hatton declare that they have no conflict of interest.

John Ryan has received speaker honorarium from Janssen and Bayer and has provided consulting services for Janssen and Bayer.

Jennalyn Mayeux has received speaker honorarium from Janssen and has participated in an advisory board for Bayer.

Human and Animal Rights and Informed Consent This article does not contain any studies with human or animal subjects performed by any of the authors.

\section{References}

1. Thenappan T, Ormiston ML, Ryan JJ, Archer SL. Pulmonary arterial hypertension: pathogenesis and clinical management. BMJ. 2018;360:j5492.

2. Maron BA, Ryan JJ. A concerning trend for patients with pulmonary hypertension in the era of evidence-based medicine. Circulation. 2019;139(16):1861-4.

3. Humbert M, Morrell NW, Archer SL, Stenmark KR, MacLean MR, Lang IM, et al. Cellular and molecular pathobiology of pulmonary arterial hypertension. J Am Coll Cardiol. 2004;43(12 Suppl S):13S$24 \mathrm{~S}$.

4. Sitbon O, Morrell N. Pathways in pulmonary arterial hypertension: the future is here. Eur Respir Rev. 2012;21(126):321-7.

5. Medarov BI, Judson MA. The role of calcium channel blockers for the treatment of pulmonary arterial hypertension: how much do we actually know and how could they be positioned today? Respir Med. 2015;109(5):557-64.

6. Klinger JR, Elliott CG, Levine DJ, Bossone E, Duvall L, Fagan K, et al. Therapy for pulmonary arterial hypertension in adults: update of the CHEST guideline and expert panel report. Chest. 2019;155(3): 565-86.

7. Amlodpine (Norvasc). package insert. New York: Pfizer Inc.; 2013.

8. Sitbon O, Humbert M, Jais X, Ioos V, Hamid AM, Provencher S, et al. Long-term response to calcium channel blockers in idiopathic pulmonary arterial hypertension. Circulation. 2005;111(23):3105-11.

9. Nifedipine (Procardia XL). package insert. New York: Pfizer Inc.; 2019.

10. Rich S, Kaufmann E, Levy PS. The effect of high doses of calcium-channel blockers on survival in primary pulmonary hypertension. N Engl J Med. 1992;327(2):76-81.

11. Diltiazem (Cardizem). package insert. Bridgewater: Bausch Health; 2020.

12. Sildenafil (Revatio). package insert. New York: Pfizer; 2020.

13. Galie N, Ghofrani HA, Torbicki A, Barst RJ, Rubin LJ, Badesch $\mathrm{D}$, et al. Sildenafil citrate therapy for pulmonary arterial hypertension. N Engl J Med. 2005;353(20):2148-57.

14. Wilkins MR, Paul GA, Strange JW, Tunariu N, Gin-Sing W, Banya WA, et al. Sildenafil versus endothelin receptor antagonist for pulmonary hypertension (SERAPH) study. Am J Respir Crit Care Med. 2005;171(11):1292-7.

15. Singh TP, Rohit M, Grover A, Malhotra S, Vijayvergiya R. A randomized, placebo-controlled, double-blind, crossover study to evaluate the efficacy of oral sildenafil therapy in severe pulmonary artery hypertension. Am Heart J. 2006;151(4):851 e1-5.

16. Simonneau G, Rubin LJ, Galie N, Barst RJ, Fleming TR, Frost $\mathrm{AE}$, et al. Addition of sildenafil to long-term intravenous epoprostenol therapy in patients with pulmonary arterial hypertension: a randomized trial. Ann Intern Med. 2008;149(8):521-30.

17. Vizza CD, Jansa P, Teal S, Dombi T, Zhou D. Sildenafil dosed concomitantly with bosentan for adult pulmonary arterial hypertension in a randomized controlled trial. BMC Cardiovasc Disord. 2017;17(1):239.

18. Tadalafil (Adcirca). package insert. Indianapolis: Eli Lilly; 2017.

19. Galie N, Brundage BH, Ghofrani HA, Oudiz RJ, Simonneau G, Safdar Z, et al. Tadalafil therapy for pulmonary arterial hypertension. Circulation. 2009;119(22):2894-903.

20. Galie N, Barbera JA, Frost AE, Ghofrani HA, Hoeper MM, McLaughlin VV, et al. Initial use of ambrisentan plus tadalafil in pulmonary arterial hypertension. N Engl J Med. 2015;373(9):834 44.

21. Ambrisentan (Letairis). package insert. Foster City: Gilead Sciences, Inc.; 2019. 
22. Galie N, Olschewski H, Oudiz RJ, Torres F, Frost A, Ghofrani $\mathrm{HA}$, et al. Ambrisentan for the treatment of pulmonary arterial hypertension: results of the ambrisentan in pulmonary arterial hypertension, randomized, double-blind, placebo-controlled, multicenter, efficacy (ARIES) study 1 and 2. Circulation. 2008;117(23):3010-9.

23. Bosentan (Tracleer). package insert. South San Francisco: Actelion; 2019.

24. Channick RN, Simonneau G, Sitbon O, Robbins IM, Frost A, Tapson VF, et al. Effects of the dual endothelin-receptor antagonist bosentan in patients with pulmonary hypertension: a randomised placebo-controlled study. Lancet. 2001;358(9288): 1119-23.

25. Rubin LJ, Badesch DB, Barst RJ, Galie N, Black CM, Keogh A, et al. Bosentan therapy for pulmonary arterial hypertension. $\mathrm{N}$ Engl J Med. 2002;346(12):896-903.

26. Humbert M, Barst RJ, Robbins IM, Channick RN, Galie N, Boonstra A, et al. Combination of bosentan with epoprostenol in pulmonary arterial hypertension: BREATHE-2. Eur Respir J. 2004;24(3):353-9.

27. Galie N, Beghetti M, Gatzoulis MA, Granton J, Berger RM, Lauer A, et al. Bosentan therapy in patients with Eisenmenger syndrome: a multicenter, double-blind, randomized, placebo-controlled study. Circulation. 2006;114(1):48-54.

28. Galie N, Rubin L, Hoeper M, Jansa P, Al-Hiti H, Meyer G, et al. Treatment of patients with mildly symptomatic pulmonary arterial hypertension with bosentan (EARLY study): a double-blind, randomised controlled trial. Lancet. 2008;371(9630):2093-100.

29. McLaughlin V, Channick RN, Ghofrani HA, Lemarie JC, Naeije $\mathrm{R}$, Packer M, et al. Bosentan added to sildenafil therapy in patients with pulmonary arterial hypertension. Eur Respir J. 2015;46(2): 405-13.

30. Macitentan (Opsumit). package insert. South San Francisco: Actelion; 2019

31. Pulido T, Adzerikho I, Channick RN, Delcroix M, Galie N, Ghofrani HA, et al. Macitentan and morbidity and mortality in pulmonary arterial hypertension. N Engl J Med. 2013;369(9): 809-18.

32. Ghofrani HA, Simonneau G, D'Armini AM, Fedullo P, Howard LS, Jais X, et al. Macitentan for the treatment of inoperable chronic thromboembolic pulmonary hypertension (MERIT-1): results from the multicentre, phase 2, randomised, double-blind, placebo-controlled study. Lancet Respir Med. 2017;5(10):78594.

33. Riociguat (Adempas). package insert. Whippany: Bayer; 2017.

34. Ghofrani HA, Galie N, Grimminger F, Grunig E, Humbert M, Jing $\mathrm{ZC}$, et al. Riociguat for the treatment of pulmonary arterial hypertension. N Engl J Med. 2013;369(4):330-40.

35. Ghofrani HA, D'Armini AM, Grimminger F, Hoeper MM, Jansa $\mathrm{P}, \mathrm{Kim} \mathrm{NH}$, et al. Riociguat for the treatment of chronic thromboembolic pulmonary hypertension. N Engl J Med. 2013;369(4): 319-29.

36. Galie N, Muller K, Scalise AV, Grunig E. PATENT PLUS: a blinded, randomised and extension study of riociguat plus sildenafil in pulmonary arterial hypertension. Eur Respir J. 2015;45(5):1314-22.

37. Selexipag (Uptravi). package insert. South San Francisco: Actelion; 2019.

38. Sitbon O, Channick R, Chin KM, Frey A, Gaine S, Galie N, et al. Selexipag for the treatment of pulmonary arterial hypertension. N Engl J Med. 2015;373(26):2522-33.

39. Orenitram Package Insert. United Therapeutics Corp, Research Triangle Park, NC 27709 USA.
40. Tapson VF, Torres F, Kermeen F, Keogh AM, Allen RP, Frantz $\mathrm{RP}$, et al. Oral treprostinil for the treatment of pulmonary arterial hypertension in patients on background endothelin receptor antagonist and/or phosphodiesterase type 5 inhibitor therapy (the FREEDOM-C study): a randomized controlled trial. Chest. 2012;142(6):1383-90.

41. Tapson VF, Jing ZC, Xu KF, Pan L, Feldman J, Kiely DG, et al. Oral treprostinil for the treatment of pulmonary arterial hypertension in patients receiving background endothelin receptor antagonist and phosphodiesterase type 5 inhibitor therapy (the FREEDOM-C2 study): a randomized controlled trial. Chest. 2013;144(3):952-8.

42. Jing ZC, Parikh K, Pulido T, Jerjes-Sanchez C, White RJ, Allen R, et al. Efficacy and safety of oral treprostinil monotherapy for the treatment of pulmonary arterial hypertension: a randomized, controlled trial. Circulation. 2013;127(5):624-33.

43. White RJ, Jerjes-Sanchez C, Bohns Meyer GM, Pulido T, Sepulveda P, Wang KY, et al. Combination therapy with oral treprostinil for pulmonary arterial hypertension. A double-blind placebo-controlled clinical trial. Am J Respir Crit Care Med. 2020;201(6):707-17.

44. Epoprostenol (Veletri). package insert. South San Francisco: Actelion; 2018.

45. Rubin LJ, Mendoza J, Hood M, McGoon M, Barst R, Williams WB, et al. Treatment of primary pulmonary hypertension with continuous intravenous prostacyclin (epoprostenol). Results of a randomized trial. Ann Intern Med. 1990;112(7):485-91.

46. Barst RJ, Rubin LJ, Long WA, McGoon MD, Rich S, Badesch $\mathrm{DB}$, et al. A comparison of continuous intravenous epoprostenol (prostacyclin) with conventional therapy for primary pulmonary hypertension. N Engl J Med. 1996;334(5):296-301.

47. Badesch DB, Tapson VF, McGoon MD, Brundage BH, Rubin LJ, Wigley FM, et al. Continuous intravenous epoprostenol for pulmonary hypertension due to the scleroderma spectrum of disease. A randomized, controlled trial. Ann Intern Med. 2000;132(6): 425-34.

48. Remodulin Package Insert. United Therapeutics Corp, Research Triangle Park, NC 27709 USA.

49. Tyvaso Package Insert. United Therapeutics Corp, Research Triangle Park, NC 27709 USA.

50. Simonneau G, Barst RJ, Galie N, Naeije R, Rich S, Bourge RC, et al. Continuous subcutaneous infusion of treprostinil, a prostacyclin analogue, in patients with pulmonary arterial hypertension: a double-blind, randomized, placebo-controlled trial. Am J Respir Crit Care Med. 2002;165(6):800-4.

51. Hiremath J, Thanikachalam S, Parikh K, Shanmugasundaram S, Bangera S, Shapiro L, et al. Exercise improvement and plasma biomarker changes with intravenous treprostinil therapy for pulmonary arterial hypertension: a placebo-controlled trial. J Heart Lung Transplant. 2010;29(2):137-49.

52. McLaughlin VV, Benza RL, Rubin LJ, Channick RN, Voswinckel R, Tapson VF, et al. Addition of inhaled treprostinil to oral therapy for pulmonary arterial hypertension: a randomized controlled clinical trial. J Am Coll Cardiol. 2010;55(18):1915-22.

53. Iloprost (Ventavis). package insert. South San Francisco: Actelion; 2019.

54. Olschewski H, Simonneau G, Galie N, Higenbottam T, Naeije R, Rubin LJ, et al. Inhaled iloprost for severe pulmonary hypertension. N Engl J Med. 2002;347(5):322-9.

55. McLaughlin VV, Oudiz RJ, Frost A, Tapson VF, Murali S, Channick RN, et al. Randomized study of adding inhaled iloprost to existing bosentan in pulmonary arterial hypertension. Am J Respir Crit Care Med. 2006;174(11):1257-63. 
56. Hoeper MM, Leuchte H, Halank M, Wilkens H, Meyer FJ, Seyfarth HJ, et al. Combining inhaled iloprost with bosentan in patients with idiopathic pulmonary arterial hypertension. Eur Respir J. 2006;28(4):691-4.

57. Galie N, Humbert M, Vachiery JL, Gibbs S, Lang I, Torbicki A, et al. $2015 \mathrm{ESC} / \mathrm{ERS}$ guidelines for the diagnosis and treatment of pulmonary hypertension: the joint task force for the diagnosis and treatment of pulmonary hypertension of the European Society of Cardiology (ESC) and the European Respiratory Society (ERS): endorsed by: Association for European Paediatric and Congenital Cardiology (AEPC), International Society for Heart and Lung Transplantation (ISHLT). Eur Respir J. 2015;46(4):903-75.

58. Giaid A, Yanagisawa M, Langleben D, Michel RP, Levy R, Shennib H, et al. Expression of endothelin-1 in the lungs of patients with pulmonary hypertension. N Engl J Med. 1993;328(24): 1732-9.

59. Sahay S, Humbert M, Sitbon O. Medical treatment of pulmonary arterial hypertension. Semin Respir Crit Care Med. 2017;38(5): 686-700.

60. Galie N, Manes A, Branzi A. Prostanoids for pulmonary arterial hypertension. Am J Respir Med. 2003;2(2):123-37.

61. Christman BW, McPherson CD, Newman JH, King GA, Bernard GR, Groves BM, et al. An imbalance between the excretion of thromboxane and prostacyclin metabolites in pulmonary hypertension. N Engl J Med. 1992;327(2):70-5.

62. Pan IZ, Carey JR, Jacobs JA, Dechand J, Sessions JJ, Sorensen T, et al. Transitioning Between Prostanoid Therapies in Pulmonary Arterial Hypertension. Front Med. 2020.

63. Rich S, Brundage BH. High-dose calcium channel-blocking therapy for primary pulmonary hypertension: evidence for long-term reduction in pulmonary arterial pressure and regression of right ventricular hypertrophy. Circulation. 1987;76(1):135-41.

64. Montani D, Savale L, Natali D, Jais X, Herve P, Garcia G, et al. Long-term response to calcium-channel blockers in nonidiopathic pulmonary arterial hypertension. Eur Heart J. 2010;31(15):1898-907.

65. Sildenafil (Viagra). package insert. New York: Pfizer Inc.; 2017.

66. Buckley MS, Staib RL, Wicks LM, Feldman JP. Phosphodiesterase-5 inhibitors in management of pulmonary hypertension: safety, tolerability, and efficacy. Drug Healthc Patient Saf. 2010;2:151-61.

67. Hoeper MM, Simonneau G, Corris PA, Ghofrani HA, Klinger JR, Langleben D, et al. RESPITE: switching to riociguat in pulmonary arterial hypertension patients with inadequate response to phosphodiesterase-5 inhibitors. Eur Respir J. 2017;50(3).

68. Gomberg-Maitland M, Bourge RC, Shapiro SM, Tarver JH 3rd, Zwicke DL, Feldman JP, et al. Long-term results of the DelIVery for pulmonary arterial hypertension trial. Pulm Circ. 2019;9(4): 2045894019878615.

69. Rahaghi FF, Feldman JP, Allen RP, Tapson V, Safdar Z, Balasubramanian VP, et al. Recommendations for the use of oral treprostinil in clinical practice: a Delphi consensus project pulmonary circulation. Pulm Circ. 2017;7(1):167-74.

70. Feldman J, Habib N, Radosevich J, Dutt M. Oral treprostinil in the treatment of pulmonary arterial hypertension. Expert Opin Pharmacother. 2017;18(15):1661-7.

71. Lim A, Wang-Smith L, Kates J, Laurent A, Kumar P, Laliberte K. The effect of different meal compositions on the oral bioavailability of treprostinil diolamine in healthy volunteers. J Clin Pharm Ther. 2013;38(6):450-5.

72. Kaufmann P, Okubo K, Bruderer S, Mant T, Yamada T, Dingemanse J, et al. Pharmacokinetics and tolerability of the novel oral prostacyclin IP receptor agonist selexipag. Am J Cardiovasc Drugs. 2015;15(3):195-203.

73. Torres F, Farber H, Ristic A, McLaughlin V, Adams J, Zhang J, et al. Efficacy and safety of ralinepag, a novel oral IP agonist, in PAH patients on mono or dual background therapy: results from a phase 2 randomised, parallel group, placebo-controlled trial. Eur Respir J. 2019;54(4).

74. Sitbon O, Jais X, Savale L, Cottin V, Bergot E, Macari EA, et al. Upfront triple combination therapy in pulmonary arterial hypertension: a pilot study. Eur Respir J. 2014;43(6):1691-7.

75. Burks M, Stickel S, Galie N. Pulmonary arterial hypertension: combination therapy in practice. Am J Cardiovasc Drugs. 2018;18(4):249-57.

76. Galie N, McLaughlin VV, Rubin LJ, Simonneau G. An overview of the 6th World Symposium on Pulmonary Hypertension. Eur Respir J. 2019;53(1).

77. Benza RL, Gomberg-Maitland M, Elliott CG, Farber HW, Foreman AJ, Frost AE, et al. Predicting survival in patients with pulmonary arterial hypertension: the REVEAL risk score calculator 2.0 and comparison with ESC/ERS-based risk assessment strategies. Chest. 2019;156(2):323-37.

78. Humbert M, Sitbon O, Chaouat A, Bertocchi M, Habib G, Gressin $\mathrm{V}$, et al. Survival in patients with idiopathic, familial, and anorexigen-associated pulmonary arterial hypertension in the modern management era. Circulation. 2010;122(2):156-63.

79. Sandoval J, Gomez-Arroyo J, Gaspar J, Pulido-Zamudio T. Interventional and surgical therapeutic strategies for pulmonary arterial hypertension: beyond palliative treatments. J Cardiol. 2015;66(4):304-14.

80. Sandoval J, Gaspar J, Pulido T, Bautista E, Martinez-Guerra ML, Zeballos M, et al. Graded balloon dilation atrial septostomy in severe primary pulmonary hypertension. A therapeutic alternative for patients nonresponsive to vasodilator treatment. J Am Coll Cardiol. 1998;32(2):297-304

81. Law MA, Grifka RG, Mullins CE, Nihill MR. Atrial septostomy improves survival in select patients with pulmonary hypertension. Am Heart J. 2007;153(5):779-84.

82. Kurzyna M, Dabrowski M, Bielecki D, Fijalkowska A, Pruszczyk P, Opolski G, et al. Atrial septostomy in treatment of end-stage right heart failure in patients with pulmonary hypertension. Chest. 2007;131(4):977-83.

83. Klepetko W, Mayer E, Sandoval J, Trulock EP, Vachiery JL, Dartevelle $\mathrm{P}$, et al. Interventional and surgical modalities of treatment for pulmonary arterial hypertension. J Am Coll Cardiol. 2004;43(12 Suppl S):73S-80S.

84. Rozkovec A, Montanes P, Oakley CM. Factors that influence the outcome of primary pulmonary hypertension. Br Heart $\mathrm{J}$. 1986;55(5):449-58.

85. Chiu JS, Zuckerman WA, Turner ME, Richmond ME, Kerstein D, Krishnan U, et al. Balloon atrial septostomy in pulmonary arterial hypertension: effect on survival and associated outcomes. J Heart Lung Transplant. 2015;34(3):376-80.

86. Galie N, Corris PA, Frost A, Girgis RE, Granton J, Jing ZC, et al. Updated treatment algorithm of pulmonary arterial hypertension. J Am Coll Cardiol. 2013;62(25 Suppl):D60-72.

87. Esch JJ, Shah PB, Cockrill BA, Farber HW, Landzberg MJ, Mehra MR, et al. Transcatheter Potts shunt creation in patients with severe pulmonary arterial hypertension: initial clinical experience. J Heart Lung Transplant. 2013;32(4):381-7.

88. Baruteau AE, Belli E, Boudjemline Y, Laux D, Levy M, Simonneau G, et al. Palliative Potts shunt for the treatment of children with drug-refractory pulmonary arterial hypertension: 
updated data from the first 24 patients. Eur J Cardiothorac Surg. 2015;47(3):e105-10.

89. Zhou L, Zhang J, Jiang XM, Xie DJ, Wang JS, Li L, et al. Pulmonary artery denervation attenuates pulmonary arterial remodeling in dogs with pulmonary arterial hypertension induced by dehydrogenized monocrotaline. JACC Cardiovasc Interv. 2015;8(15):2013-23.

90. Huang Y, Liu YW, Pan HZ, Zhang XL, Li J, Xiang L, et al. Transthoracic pulmonary artery denervation for pulmonary arterial hypertension. Arterioscler Thromb Vasc Biol. 2019;39(4):704 18.

91. Chen SL, Zhang FF, Xu J, Xie DJ, Zhou L, Nguyen T, et al. Pulmonary artery denervation to treat pulmonary arterial hypertension: the single-center, prospective, first-in-man PADN-1 study (first-in-man pulmonary artery denervation for treatment of pulmonary artery hypertension). J Am Coll Cardiol. 2013;62(12): 1092-100.

92. Rothman AMK, Vachiery JL, Howard LS, Mikhail GW, Lang IM, Jonas M, et al. Intravascular ultrasound pulmonary artery denervation to treat pulmonary arterial hypertension (TROPHY1): multicenter, Early Feasibility Study. JACC Cardiovasc Interv. 2020;13(8):989-99.

93. Engelfriet PM, Duffels MG, Moller T, Boersma E, Tijssen JG, Thaulow E, et al. Pulmonary arterial hypertension in adults born with a heart septal defect: the euro heart survey on adult congenital heart disease. Heart. 2007;93(6):682-7.

94. Vogel M, Berger F, Kramer A, Alexi-Meshkishvili V, Lange PE. Incidence of secondary pulmonary hypertension in adults with atrial septal or sinus venosus defects. Heart. 1999;82(1):30-3.

95. Stout KK, Daniels CJ, Aboulhosn JA, Bozkurt B, Broberg CS, Colman JM, et al. 2018 AHA/ACC guideline for the Management of Adults with Congenital Heart Disease: executive summary: a report of the American College of Cardiology/American Heart Association Task Force on Clinical Practice Guidelines. J Am Coll Cardiol. 2019;73(12):1494-563.

96. Jain S, Dalvi B. Atrial septal defect with pulmonary hypertension: when/how can we consider closure? J Thorac Dis. 2018;10(Suppl 24):S2890-S8

97. Orens JB, Estenne M, Arcasoy S, Conte JV, Corris P, Egan JJ, et al. International guidelines for the selection of lung transplant candidates: 2006 update-a consensus report from the Pulmonary Scientific Council of the International Society for Heart and Lung Transplantation. J Heart Lung Transplant. 2006;25(7):745-55.

98. Chen H, Shiboski SC, Golden JA, Gould MK, Hays SR, Hoopes $\mathrm{CW}$, et al. Impact of the lung allocation score on lung transplantation for pulmonary arterial hypertension. Am J Respir Crit Care Med. 2009;180(5):468-74

99. Yusen RD, Edwards LB, Dipchand AI, Goldfarb SB, Kucheryavaya AY, Levvey BJ, et al. The registry of the International Society for Heart and Lung Transplantation: thirtythird adult lung and heart-lung transplant report-2016; focus theme: primary diagnostic indications for transplant. J Heart Lung Transplant. 2016;35(10):1170-84.

100. Humbert M, Sitbon O, Simonneau G. Treatment of pulmonary arterial hypertension. N Engl J Med. 2004;351(14):1425-36.

101. Guignabert C, Tu L, Girerd B, Ricard N, Huertas A, Montani D, et al. New molecular targets of pulmonary vascular remodeling in pulmonary arterial hypertension: importance of endothelial communication. Chest. 2015;147(2):529-37.

102. Humbert M, Guignabert C, Bonnet S, Dorfmuller P, Klinger JR, Nicolls MR, et al. Pathology and pathobiology of pulmonary hypertension: state of the art and research perspectives. Eur Respir J. 2019;53(1).
103. Sitbon O, Gomberg-Maitland M, Granton J, Lewis MI, Mathai $\mathrm{SC}$, Rainisio M, et al. Clinical trial design and new therapies for pulmonary arterial hypertension. Eur Respir J. 2019;53(1).

104. Sommer N, Ghofrani HA, Pak O, Bonnet S, Provencher S, Sitbon $\mathrm{O}$, et al. Current and future treatments of pulmonary arterial hypertension. Br J Pharmacol. 2020.

105. Tamura Y, Phan C, Tu L, Le Hiress M, Thuillet R, Jutant EM, et al. Ectopic upregulation of membrane-bound IL6R drives vascular remodeling in pulmonary arterial hypertension. J Clin Invest. 2018;128(5):1956-70.

106. Steiner MK, Syrkina OL, Kolliputi N, Mark EJ, Hales CA, Waxman AB. Interleukin-6 overexpression induces pulmonary hypertension. Circ Res. 2009;104(2):236-44.

107. Price LC, Wort SJ, Perros F, Dorfmuller P, Huertas A, Montani D, et al. Inflammation in pulmonary arterial hypertension. Chest. 2012;141(1):210-21.

108. Le Hiress M, Tu L, Ricard N, Phan C, Thuillet R, Fadel E, et al. Proinflammatory signature of the dysfunctional endothelium in pulmonary hypertension. Role of the macrophage migration inhibitory factor/CD74 complex. Am J Respir Crit Care Med. 2015;192(8):983-97.

109. Tian W, Jiang X, Tamosiuniene R, Sung YK, Qian J, Dhillon G, et al. Blocking macrophage leukotriene $\mathrm{b} 4$ prevents endothelial injury and reverses pulmonary hypertension. Sci Transl Med. 2013;5(200):200ra117.

110. Qian J, Tian W, Jiang X, Tamosiuniene R, Sung YK, Shuffle EM, et al. Leukotriene B4 activates pulmonary artery adventitial fibroblasts in pulmonary hypertension. Hypertension. 2015;66(6): 1227-39.

111. Trankle CR, Canada JM, Kadariya D, Markley R, De Chazal HM, Pinson J, et al. IL-1 blockade reduces inflammation in pulmonary arterial hypertension and right ventricular failure: a single-arm, open-label, phase IB/II pilot study. Am J Respir Crit Care Med. 2019;199(3):381-4.

112. Hernandez-Sanchez J, Harlow L, Church C, Gaine S, Knightbridge E, Bunclark K, et al. Clinical trial protocol for TRANSFORM-UK: a therapeutic open-label study of tocilizumab in the treatment of pulmonary arterial hypertension. Pulm Circ. 2018;8(1):2045893217735820.

113. Blum LK, Cao RRL, Sweatt AJ, Bill M, Lahey LJ, Hsi AC, et al. Circulating plasmablasts are elevated and produce pathogenic anti-endothelial cell autoantibodies in idiopathic pulmonary arterial hypertension. Eur J Immunol. 2018;48(5):874-84.

114. Nicolls M, Badesch D, Chung L, Domsic TR, Medsger T, Pinckney A, et al. Safety and efficacy of B-cell depletion with rituximab for the treatment of systemic sclerosis-associated pulmonary arterial hypertension in a multi-center NIH clinical trial [abstract]. American College of Rheumatology; Atlanta, Georgia: Arthritis Rheumatol.; 2019.

115. Bowers R, Cool C, Murphy RC, Tuder RM, Hopken MW, Flores $\mathrm{SC}$, et al. Oxidative stress in severe pulmonary hypertension. Am J Respir Crit Care Med. 2004;169(6):764-9.

116. Irodova NL, Lankin VZ, Konovalova GK, Kochetov AG, Chazova IE. Oxidative stress in patients with primary pulmonary hypertension. Bull Exp Biol Med. 2002;133(6):580-2.

117. Rol N, Kurakula KB, Happe C, Bogaard HJ, Goumans MJ. TGFbeta and BMPR2 signaling in PAH: two black sheep in one family. Int J Mol Sci. 2018;19(9).

118. Yung LM, Nikolic I, Paskin-Flerlage SD, Pearsall RS, Kumar R, Yu PB. A selective transforming growth factor-beta ligand trap attenuates pulmonary hypertension. Am J Respir Crit Care Med. 2016;194(9):1140-51. 
119. Joshi SR, Liu J, Pearsall RS, Li G, Kumar R. ACTRIIA (sotatercept) reverses pulmonary vascular remodeling to attenuate pulmonary arterial hypertension (PAH) by rebalancing TGF-b/ BMP singaling in a preclinical model. Am J Respir Crit Care Med. 2019;199(A4395).

120. Yung LM, Pearsall RS, Bocobo G, Sako DS, Dinter T, Kumar R, et al. Editors. ACTRIIA-fc rebalances BMP and activin/TGF-b signaling to attenuate experimental pulmonary hypertension. Anaheim: American Heart Association Scientific Sessions; 2017.

121. Hoeper MM, Barst RJ, Bourge RC, Feldman J, Frost AE, Galie N, et al. Imatinib mesylate as add-on therapy for pulmonary arterial hypertension: results of the randomized IMPRES study. Circulation. 2013;127(10):1128-38.

122. Frost AE, Barst RJ, Hoeper MM, Chang HJ, Frantz RP, Fukumoto $\mathrm{Y}$, et al. Long-term safety and efficacy of imatinib in pulmonary arterial hypertension. J Heart Lung Transplant. 2015;34(11): 1366-75.

123. Galkin A, Clemons B, Garcia E, Brooks J, Slee D, Salter-Cid L, et al. Gb002, a novel inhaled pdgfr kinase inhibitor, demonstrates efficacy in the su5416 hypoxia rad model of pulmonary arterial hypertension $(\mathrm{PAH})$. Philadelphia: Circulation: American Heart Association Scientific Sessions; 2019.

124. Simonneau G, Montani D, Celermajer DS, Denton CP, Gatzoulis MA, Krowka M, et al. Haemodynamic definitions and updated clinical classification of pulmonary hypertension. Eur Respir J. 2019;53(1).
125. Strange G, Playford D, Stewart S, Deague JA, Nelson H, Kent A, et al. Pulmonary hypertension: prevalence and mortality in the Armadale echocardiography cohort. Heart. 2012;98(24):1805-11.

126. Rosenkranz S, Gibbs JS, Wachter R, De Marco T, VonkNoordegraaf A, Vachiery JL. Left ventricular heart failure and pulmonary hypertension. Eur Heart J. 2016;37(12):942-54.

127. King CS, Nathan SD. Pulmonary hypertension due to interstitial lung disease. Curr Opin Pulm Med. 2019.

128. Vachiery JL, Tedford RJ, Rosenkranz S, Palazzini M, Lang I, Guazzi M, et al. Pulmonary hypertension due to left heart disease. Eur Respir J. 2019;53(1).

129. Nathan SD, Barbera JA, Gaine SP, Harari S, Martinez FJ, Olschewski $\mathrm{H}$, et al. Pulmonary hypertension in chronic lung disease and hypoxia. Eur Respir J. 2019;53(1).

130. Nathan SD, Flaherty KR, Glassberg MK, Raghu G, Swigris J, Alvarez R, et al. A randomized, double-blind, placebo-controlled study to assess the safety and efficacy of pulsed, inhaled nitric oxide at a dose of $30 \mathrm{mug} / \mathrm{kg}$ ideal body weight $/ \mathrm{hr}$ in subjects at risk of pulmonary hypertension associated with pulmonary fibrosis receiving oxygen therapy. Chest. 2020.

Publisher's Note Springer Nature remains neutral with regard to jurisdictional claims in published maps and institutional affiliations. 